\title{
Actinide-Specific Complexing Agents: Their Structural and Solution Chemistry
}

by

\author{
Kenneth N. Raymond, Gwen E. Freeman, and Mary J. Kappel \\ Department of Chemistry and Materials and Molecular Research Division, \\ Lawrence Berkeley Laboratory, University of California, \\ Berkeley, California 94720
}

\section{DISClalMER}

This repon was prepared a an sccount of work sponsored by an seacy of the Uisited States Government. Neilher the United States Government nor any agency therool, nor any of their employes, makes any warranty, expreas or implied, or arumes any lezal liability or reaponsibility for the securacy, completenes, or usefuluen of any information, apperalus, product, or process disclosed, or represents that its use would not iafriage privately owned rigbus Refetence hercin to any specilic commercial product, procew, of service by trede name, itadematk. manufscturet, of otherwase does not necesurily coentitute or imply its endonemeat. recommendation, or favoring by the United Stetes Governmeat or any ascacy theroof. The viess and opinions of authorl expreand bercin do not aecescasily state or reflect those of the Unitod State Government or any agency theroof.

\section{MASTER}

This work was supported by the Jirector, Office cf Energy Researsn, Office of Basic Energy Sciences. Chemical Sciences Division of ere U.S. Department of Energy under Contract number DE-ACD3-76SFDCosa 


\section{Introduction}

With the commercial development of nuclear reactors, the actinides have become important industrial elements. A major concern of the nuclear industry is the biological hazard associated with nuclear fuels and their wastes. ${ }^{1,2}$ In addition to their chemical toxicity, the high specific activity of alpha emission exhibited by the common isotopes of the transuranium elements make these elements potent carcinogens when incorporated. $^{3-7}$ Since biological systems are unable to detoxify metal ions by metabolic degrajation, they instead must be excreted or immobilized. ${ }^{8}$ Unfortunately, only a small portion of absorbed tetra- or trivalent actinide is eliminated from a mamalian body during its lifetime. The remaining actinide is distributed throughout the body but is especially found fixed in the liver and in the skeleton. $5,7,9-12$ While the ability of some metals to do damage is greatly reduced by immobilization, local high concentrations of redioactivity are produced by immobilized actinides - thereby increasing the absorbed radiation dose and carcinogenic potential. Removal of actinides from the body is therefore an essential component of treatment for actinide contamination.

Conventional chelating agents such as diethylenetriaminepentaacetic acid, DTPA, remcre much of the soluble actinide present in body fluids, but are almost totally ineffective in removing the actinide after it has left the circulation or after hydrolysis of the metal to form colloids and polymers. ${ }^{13-15}$ The inability of DTPA to completely coordinate the tetravalent actinides is shown by the easy formation of ternary comjiexes between in(DTPA) and many bidentace ligands. ${ }^{16-18}$ The iydrolys is of in(IV) and U(IY) DTPA complexes at pH near $\sigma$ is explained by the 
dissociation of $\mathrm{H}^{+}$from a coordinated water molecule. ${ }^{19-22}$ In addition, the polyaminocarboxylic acids are relatively toxic because they indiscriminately complex and remove biologically important metals, especially zinc. 23-26 Thus there is a need to develop new and powerfut chelating agents highly specific for tetravalent actinides, particularly $\mathrm{Pu}(I V)$.

While not the most toxic, plutonium is the most likely transuranium element to be encountered. Plutonium commonly exists in aqueous solution in each of the oxidation states from III to VI. However, under biological conditions redox potentials, complexation, and hydrolysis strongly favor $\mathrm{Pu}$ (IV) as the dominant species. ${ }^{27,28}$ For this reason, the early work of our research group focused on developing sequestering agents specific for $\mathrm{Pu}(\mathrm{IV})$ and the other tetravalent actinide ions.

There are remarkable similarities between $\mathrm{Pu}(\mathrm{V})$ and $\mathrm{Fe}(\mathrm{TII})$ (Figure 1). These include the similar charge per ionic radius ratios for fe(III) and $P u(I V)$ ( 4.6 and $4.2 \mathrm{e} / \AA$, respectively), and the formation of highly insoluble hydroxides. They also have similar transport properties in mamna 15 ; the majority of soluble Pu(IV) present in body fluids is rapidly bound by the iron transport protein transferrin at the site which nomally binds Fe(III). In Tiver cells, deposited plutonium is initially bound to the iron storage protein ferritin and eventuaily becomes associated with hemosiderin and other long-tern iron siorage proteins. $9,29,30$ These similarities of $\mathrm{Pu}(\mathrm{IV})$ and $\mathrm{Fe}(: I I)$ suggested to us a biomimetic approach to the design of $P u(i V)$ sesuestering agen:s modeled after the very efficient and highly specific iron sequestering jgents, siderophores. which are used by zacteria and other microorganisms to obtain fe(t:1) from the enviroment. $31-33$ 
The siderophores (Figure 2) typically contain hydroxamate or catecholate functional groups which are arranged to form an octahedral cavity the exact size of a ferric ion. Catechol (2,3-dihydroxybenzene) and the hydroxamic acids ( $\mathrm{N}$-hydroxyamides) are very weak acids that ionize to form "hard" oxygen anions, which bind strongly to strong Lewis acids such as $\mathrm{Fe}$ (III) and $\mathrm{Pu}$ (IV). Complexation by these groups forms five-membered chelate rings, which substantialiy increases their stability compared to complexation by lone oxygen anions. 34 Due to its higher charge and strong basicity, the catecholate group forms even stronger complexes with the tetrayalent actinides than the hydroxamate anion. Thus our initial goal was the incorporation of catecholate functional groups into multidentate chelating agents that specifically encapsulate tetravalent actinides. This has led to the examination of the solution chemistry of Pu(III) and (IV) with catechol and catecholate ligands.

In addition, we have recently examined the relatively unknown catecholate coordination chemistry of the trivalent actinide ions in order to understand the unusual excretion behavior of americium(III) observed in mice and dogs treated with catecholate ligands we have developed. ${ }^{35,36}$ It was initially thought that this behavior resulted from the tetracatechoylamide ligands stabilizing the americium(IV) oxidation state, but we have recently shown ${ }^{36}$ that americium exists in the trivalent state in catecholate complexes. Al though the early zransuranium actinides exhibit a wide variety of oxidation states, in their trivalent state they have ionic radii and chemical properties similar to the trivalent lanthanides in the same column of the periodic 
table. ${ }^{37}$ Since the stability and coopdination chemistry of metal catecholate complexes are largely determined by the metal's charge to ionic radius ratio 38,39 we have begun to explore the lanthanide(III) catecholates as models for actinide(III) catecholate complexes. 40,41

The similarity between $\mathrm{Fe}$ (III) and actinide(IV) ions ends with their coordination numbers. Because of the larger ionic radii of the actinide(IV) ions, their preferred coordination number is eight or more (higher coordination numbers usually occur with very small ligands or by the incorporation of a solvent molecule $e^{42,43}$ ). The two stable highsymetry eight-coordinate geometries are the square antiprism $\left(D_{4 d}\right)$ and the trigonat faced dodecahedron $\left(D_{2 d}\right)$. The coulombic energy differences between these polyhedra (Figure 3 ) is very small and the preferred geometry is largely determined by steric requirements and ligand field effects. Cubic coordination lies at higher energy because of higher ligand-ligand interactions and thus is seen only in the solid state. Another important eight-coordinate polyhedron, the bicapped trigonal prism $\left(c_{2 v}\right)$, corresponds to an energy minimum along the transformation pathway between the square antiprism and the dodecahedron. ${ }^{44-49}$ The $\mathrm{mmm}$ isomer of the trigonal faced dodecahedron is the most prevalent polyhedron in the solid state.

Actinide Catecholates

Two fundamental questions in the design of an actinide-specific seques tering agent are the coordination number and gecmetry actually preferred by the metal ion with a given ligand. The complexes formed by $T h(I V)$ or $U(I V)$ and catechal, in which the steric restraints of a macrochelate are absent, serve as structural archetjpes for designing 
the optimum actinide(IV) sequestering agent. Thus the structures of an isoelectronic, isomorphous series of tetrakis-catecholato salts, $\mathrm{Na}_{4}\left[M\left(\mathrm{C}_{6} \mathrm{H}_{4} \mathrm{O}_{2}\right)_{4}\right] \cdot 21 \mathrm{H}_{2} \mathrm{O} ; \mathrm{M}=\mathrm{Th}$ (IV), U(IV), $\mathrm{Ce}$ (IV), and $\mathrm{Hf}$ (IV), were determined by single crystal $x$-ray diffraction. Suitable crystals were isolated from the reaction of the metal chlorides or nitrates and the disodium salt of catechol in aqueous solution under an inert atmosphere. 50,51 Measurement of magnetic susceptibility and electronic spectra of the cerium and uranium complexes verified the presence of the +4 oxidation state.

It 15 somewhat surprising that the strongly oxidizing $\mathrm{Ce}(\mathrm{IV})$ ion $\left(E_{0}=+1.70 \mathrm{~V}\right)^{52}$ did not react with the catechol dianion, a facile reducing agent. 53 The ability of catechol to coordinate, without reduction, oxidizing ions as Ce(IV), Fe(III), ${ }^{54} V(V),{ }^{55}$ and $M n(I I I)^{56}$ is a reflection of this ligand's impressive coordinating ability. The Ce(IV) complex was found by differential pulse voltammetry to undergo a quasireversible one-electron reduction in strongly basic solution in the presence of excess catechol. The measured potential of this was - 488 my vs NHE. This enormous shift of the redox potential of the Ce(IV)/ Ce(III) couple is dramatic evidence of the enomous affinity of the catecholate anion for the tetravalent lanthanides and actinides. 57 More details of this system and the $\mathrm{Pu}$ (IV)/Pu(III) couple wiil be given later.

The crystal structure of this isostructural series of catechol complexes consists of discrete $\left[M(\text { catechol })_{4}\right]^{4-}$ dodecahedra, a hydrogen bonded network of 21 waters of crystallization and sodium ions, each of 
which is bonded to two catecholate oxygens and four water oxygens. Of the possible eight coordinate polyhedra, anly the cube and the dodecahedron allow the presence of the crystallographic $\overline{4}$ axis on which the metal ion sits. As depicted in Figure 4 the tetrakis (catecholato) complexes nearly display the ideal $D_{2 d}$ molecular symmetry of the mimmisomer of the trigonal-faced dodecahedron.

\section{Actinide Sequestering Agents}

With the geometric considerations just described in mind, four 2,3dihydroxybenzoic acid groups were attached to a series of linear tetraamines via amide linkages as shown schematically in Figure 5. Cyclic tetramine backbones were also used. However the greater stereochemical freedom effected by linear tetraamine backbones yielded chelates significantly more effective in removing Pu(IV) from mice. 58

The introduction of anionic electron-withdrawing substituents in the 2,3-dihydroxybenzoyl group of the ligand (Figure 6) improves their water solubility, stability to air oxidation, and affinity for the actinide(IV) ion at low pH. This initially was achieved by sulfonation in the 5-position but has also been done by introducing a carboxylate group in the 4-position (Figure 6 ), ${ }^{59}$ the latter also provides another potential iigating group.

Gadolinium is iocated in the lanthanide series one column to the right of europium, the homolog of americium. The structural chemistry of gadolinium(III) with catechol was examined ${ }^{40}$ to compare $i t s$ unconstrained coordination geometry with that of the tetravalent actinides and lanthanides. The structure of i tetrakiscatecholato salt, $\mathrm{Ka}_{5}\left[\mathrm{Gd}(\mathrm{ca:})_{4}\right]$. $19.2 \mathrm{H}_{2} \mathrm{O}$ was determined by single crystal $\mathrm{X}$-ray diffraction and proved 
to be nearly isomorphous with the tetrakis catecholate complexes with the tetravalent actinides discussed previously. The gadolinium tetracatechoiate complex consists of discrete $\left[\mathrm{Gd}(\text { catechol })_{4}\right]^{5-}$ dodecahedra (as depicted in Figure 4), a hydrogen-bonded network of 19.2 waters of crystallization and sodium ions. Each of four of the sodium ions are bonded to two catecholate oxygens and four water oxygens, as with the M(IV) structures; the fifth sodium atom is disordered and prevents some of the waters from having a full occupancy, which results in the fractional value of 19.2 waters.

Crystals of $\left[\mathrm{Gd}(\mathrm{catechol})_{4}\right]^{5-}$ were isolated from the reaction of the metal nitrate and a $50 \%$ excess of the disodium salt of catechol in aqueous, approximately $2 M$ cótecnulate solution under an inert atmosphere. ${ }^{40}$ Such forcing conditions of high $\mathrm{pH}$ and excess catechol were necessary to obtain the tetrakis catecholate complex.

If a smaller ratio of catechol to metal is used (e.g., three or four to one) the dimeric complex $\mathrm{Na}_{6}\left[\mathrm{Gd}(\text { catechol })_{3}\right]_{2} \cdot 2 \mathrm{OH}_{2} \mathrm{O}$ is obtained. The structure of this complex was determined by single crystal $X$-ray diffraction. It consists of discrete units of $\left[\mathrm{Gd}(\mathrm{cat})_{3}\right]_{2}^{6-}$ dimers (Figure 7). The sodium atoms and twenty waters of crystallization are in infinite bridging chains involving some of the catecholate oxygens. This bonding network greatly increases the compound's resistance to air oxidation in the solid state. Each gadolinium atom is seven coordinate and the dimer has tro bridging catecholates.

The chemistry of the isolated Gd(III) complexes parallels aspects of the catechol solution chemistry of cerium and plutonium as seen electrochemically. Previous work $51,60,61$ demonstrated that cacechols are very good at stabilizing nigher oxidation states of metal ions. In 
fact, the potentials of the uncomplexed ions, normally obtained in noncoordinating acidic media, are known to shift negative in excess of 2.0 volts upon complexation of catechol in basic solution. This brings the $\mathrm{Ce}$ and $\mathrm{Pu}$ (IV)/(III) reduction potential well within the operating range of a hanging mercury drop electrode in base. 62

By varying ligand concentrations and $\mathrm{pH}$ of Ce- and Pu-catecholate solutions, electrochemistry can be used to elucidate not onily the relative stability of $M$ (IV) versus $M$ (III) complexes, but also to study the protonation behavior and stoichiometry of complexes. 63 Utilizing differential pulse voltammetry, ${ }^{64}$ these studies can be carried out in dilute solution (less than $0.2 \mathrm{mM}$ in $\mathrm{Pu}$ ).

M(IV)/(III) Catechol Electrochemistry

The low acidity of catechol requires that the electrochemical experiments be conducted under very basic conditions. The measurements of electrochemical potential as a function of ligand concentration were always maintained at $\mathrm{pH}$ values $>12.3$. Above this $\mathrm{pH}$ the potential is independent of $\mathrm{pH}$ and demonstrates only a ligand dependence. A large negative shift in potential for increasing total catechol concentrations is observed for Pu-catecinol as compared to Pu(IV)/Pu(III) (+ 0.98 V vs NHE) in acidic medium. 65 This indicates a stabilization of the tetravalent ion relative to the trivalent ion by catechol. Similar stabilization of the $\mathrm{Ce}(\mathrm{IV}) / \mathrm{Ce}$ (III) couple with catechol is observed. 51 In addition, a simflar negative shift in potential with increasing total ligand concentration is seen. Both systems are classified as quasireversible, since there is a dependence of peak potential on scan rate. However at the slow scan rates employed here the electrode kinetics are reversible. 
If the composition of the oxidized metal complex is known, the variation of fotential of an electroactive metal complex with increasing ligand concentration gives information on the stoichiometry of the reduced metal complex which is formed. ${ }^{63}$ for plutonium, using the two half reactions $\left(\mathrm{L}^{2-}=\right.$ catechol $\left.^{2-}\right)$

$$
\begin{aligned}
P u(I V)+e^{-} & =P u(I I I) \quad E_{0}=+0.98 V \text { VS. NHE } \\
P u(I V) L_{4}^{4-}+e^{-} & =P u(I I I) L_{q}^{3-2 q}+(4-q) L^{2-}
\end{aligned}
$$

and the two dissociation constants

$$
K_{I V}=\frac{[P U(I V)]\left[L^{2-}\right]^{4}}{\left[P U(I V):_{4}^{4-}\right]} \quad K_{I I I}=\frac{[P(I I I)]\left[L^{2-}\right]^{q}}{\left[P U\left(I I I I L_{q}{ }^{3-2 q}\right]\right.}
$$

A Nernstian expression can be written which includes a dependence on total ligand concentration $\left(\mathrm{L}_{T}\right)$ assuming reversible electrode kinetics at $25^{\circ} \mathrm{C}$

$$
E_{0}-E_{f}=0.059\left[\log \left(\frac{K_{I V}}{K_{I I I}}\right)-(4-q) \log L_{T}\right]
$$

Differentiation of this equation gives

$$
d\left(E_{f}\right) / d\left(\log L_{T}\right)=-0.059(4-q)
$$

Thus, a plot of potential versus the $\log$ of the total ligand concentrazion gives a line with a slope containing the value of $4-q$, where $q$ is the stoichiometric coefficient for H(III) catechol complexes. If the stoichiometry of the $M$ (III) catechol complex is the same as that for the $M(I V)$ catechol complex, there would be no variation of $\varepsilon_{f}$ with total ligand concentration and the total potential shift would be proportional 
to $\log \left(K_{I V} / K_{I I I}\right)$. Such a plot for cerium catechol is illustrated by Figure 8 . The slope of this line indicates $q=2.5$. This implies a $M$ (III) catechol complex of lower stoichionetry than the $M$ (IV) catechol complex with two alternate interpretations: either under the conditions specified the M(III) complex may involve 2.5 catechols or at this $\mathrm{pH}$ there exists an equilibrium between the biscatechclate and triscatecholate complex. These results alter earlier interpretations regarding cerium catechol electrochemistry. 51 This previous study did not include an investigation of the ligand dependence of the potential, but rather measured a potential in $5 \mathrm{M} \mathrm{NaOH}$ and $1 \mathrm{M}$ catechol assuming the $\mathrm{Ce}$ (III) complex was a tetracatechol complex. The value reported (- $692 \mathrm{mV}$ vs SCE) is included as a point in Figure 8, indicating that the same ligand dependence on the potential exists at these extreme conditions. However, there appears to be no shift in potential above catechol concentrations or $2 \mathrm{M}(5 \mathrm{M} \mathrm{KOH})$ which means that under these forcing conditions a tetrakis(catecholato) complex of Ce(III) $F$ edominates in solution. The reduction potential for the $\mathrm{Ce}$ (IV)/Ce(III)-(catechol) couple is - $732 \mathrm{mV}$ vS SCE and implies a ratio of $K(I V) / K$ (III) of $10^{41}$.

The plot of potential versus the $\log$ of the total ligand concentration for plutonium-catechol (Figure 9) is very similar to that observed for cerium-catechol. The slope of that line again indicates that $q=2.5$. Although the electrorhemistry of these systems show quasi-reversible behavior, theory developed for reversible systems ${ }^{63}$ appears to apply.

Al though a graat deal of effort has been expanded to synthesize catecholate 1 gands which are octadentate(tetracatecholates) and capable of encapsulatiny actinide(IV) ions, $59,66,67$ previously there has been 
no direct evidence about the nature of complexes formed - aside from the fact that 3,4,3-LICAMS and 3,4,3-LICAMC (Figure 6) effectively complex Pu(IV) in vivo and promote excretion. 58,59 The results of the first in vitro experiments of plutonium with catecholate ligands have recentiy been obtained.

Upon addition of Pu(IV) to a solution of 3,4,3-LICAMS at high $\mathrm{pH}$ (> 12) a fairly intense amber color is observed due to a broad charge transfer vand at $435 \mathrm{~nm}\left(s=750 \mathrm{M}^{-7} \mathrm{~cm}^{-1}\right)$. This same color is observed for Pu(IV) catechol at high $\mathrm{pH}$. Lowering the $\mathrm{pH}$ of the $\mathrm{Pu}(\mathrm{IV})-3,4,3-$ LICAMS (pH 10.9) shifts $\lambda_{\max }$ to $441 \mathrm{~nm}\left(\varepsilon=460 \mathrm{M}^{-1} \mathrm{~cm}^{-1}\right.$ ), similar to the shifts and intensity loss seen for Fe(III)-3,4-LICAMS upon protonation. ${ }^{68}$ Complexes of $\mathrm{CE}(\mathrm{IV})(\mathrm{cat})_{4}{ }^{4-}$ are purple, ${ }^{51}$ as is the Ce(IV)$3,4,3$-LICAMS complex at high $\mathrm{pH}\left(i_{\max }=514 \mathrm{~nm}, \varepsilon=4400 \mathrm{M}^{-1} \mathrm{~cm}^{-1}\right)$. Thus at high $\mathrm{pH}(>12)$ the 3,4,3-LICAMS complexs of Pu(IV) and CeiIV) seem to be tetracatecholate complexes.

The negative shifts in potential for the Pu(IV)- and Ce(IV)-3,4,3LICAMS complexes as compared to free $M($ IV)/(III) are given in figure 10. The shifts are larger than those observed with catechor. The potential of the Pu(IV)/(III)- and Ce(IV)/(III)-3,4,3-LICAMS couple does not appear to shift with increasing ligand concentration. This could mean all four catecholate groups are bound. However if upon reduction of the metal center to $M(I I I)$ the number of catecholate groups bound decreases (as in the Pu and Ce catechol studies;, this change would not be reflected in a change of potential with varying total ligand concertration. A shift in potential dependent on total ligand concentrotion will occur only if stoichiometries other than $1: 1$ occur. 
If the PU(III)-3,4,3-LiCAMS complex is similar to the PU(III) catechol complex, at high $\mathrm{pH}$ there are one or possibly two pendant arms of the macrochelate which are unbound and deprotonated. Figure 11 shows the differential pulse voltammograms of $\mathrm{Pu}$ (IV)-3,4,3-LICAMS as a function of $\mathrm{pH}$. A positive shift in potential and a loss of current is seen between $\mathrm{pH} 10.8$ and $\mathrm{pH} 6.5$, whereas a small shift in potential and a small loss of current is observed between pH 12.1 and $\mathrm{pH} 11.0$. Precipitation is evident at $\mathrm{pH} 9.4$ and increases as the $\mathrm{pH}$ is lowered. This dependence of potential on ph can be due to either the acidity of the oxidized complex (and $E_{1 / 2}$ is only independent of $\mathrm{pH}$ in regions of low $\mathrm{pH}$ ) or the acidity of the raduced complex (and $\mathrm{E}_{1 / 2}$ is only independent of $\mathrm{pH}$ in regions of $h i g h \mathrm{pH}) .^{36}$ A plot of $E_{1 / 2}$ versus $\mathrm{pH}$ for $\mathrm{Pu}(3,4,3$-LICAMS) is shown in Figure 12 . It shows a region at high $\mathrm{pH}$ with very little change in $E_{1 / 2}$ and a region between $\mathrm{pH} 10.8$ and 6.5 with a slope of -0.053 . This corresponds to a one proton equilibrium ${ }^{36}$ involving the acidity of the reduced species. The intersection of the two lines is at $\mathrm{pH}=\mathrm{pK}_{\mathrm{a}}=11.0$. If the Pu(III)-3,4,3-LICAMS has one or two pendant catechol arms free, this $\mathrm{pK}_{\mathrm{a}}$ corresponds very well with the protonation of a phenolic oxygen meta to the carbonyl. In the free ligand, with no metal bound, this $\mathrm{pK}_{\dot{a}}$ is estimated to be about $11.5 .^{69}$ Very similar results are observed for $\mathrm{Pu}(3,4,3$-LICAMC $)$ but with one notable difference, the phenolic oxygens of 3,4,3-LICAMC are considerabiy less acidic than shose of the sulfonated ligand. 70 Thus, the protonation constants of the complexes are considerably higher.

The derrease in peak current with decreasing $\mathrm{pH}$ observed in Figure 11 can alsu be attributed to a frotonation phenomenon, but the protonation here involves the Pu(IV)-3,4,3-LICAMS complex. The bulk solution 
contains the Pu(IV) complex and the peak current is directly proportiona] to the concentration. For differential pulse at a stationary electrode the peak current can be expressed as 71

$$
\Delta i_{p}=\frac{n F A D^{l / 2} c}{\pi / 2 t / / 2} \cdot \frac{1-B}{1+B}
$$

where

$$
\begin{aligned}
& n=\text { number of electrons } \\
& F=\text { Faraday constant } \\
& A=\text { electrode area } \\
& D=\text { diffusion coefficient of bulk electroactive species } \\
& C=\text { concentracion of bulk electroactive species } \\
& t=\text { puise width } \\
& B=\exp [\mathrm{nF} / \mathrm{RT} \Delta \mathrm{E}] ; \Delta E=\text { pulse height }
\end{aligned}
$$

Thus, one can consider that for two electroactive species in solution with differing diffusion coefficients the peak current is

$$
\Delta i_{p}=k D_{1}^{1 / 2} c_{1}+k D_{2}^{1 / 2} c_{2}
$$

where $k$ is a constant containing the aforementioned parameters. Consider that $c_{1}$ and $c_{2}$ be related by a protonation equilibrium

$$
K_{H}=\frac{c_{1}\left[H^{+}\right]^{n}}{c_{2}}
$$

and that $c_{T}=c_{1}+c_{2}$. For this relationship an expression can be developed

$$
\Delta i_{p}=k 0_{2}^{1 / 2} c_{T}+\frac{\left(\Delta i_{p}{ }^{2}-\Delta i_{p}\right) K H}{\left[H^{+}\right]^{n}}
$$


where

$\Delta i_{p}{ }^{0}=$ the peak current at high pH with only species $c_{1}$ present

$\Delta i_{p}=$ the peak current at any $p H$ other than $i_{p}{ }^{\circ}$ where $c_{1}$ and $c_{2}$ are in equilibrium

This is analogous to an expression developed ty Schwarzenbach for VIS-UV spectra, only in this case diffusion coefficients rather than extinction coefficients are used. 72

A plot of $\Delta i_{p}$ versus $\left(\Delta i_{p}^{\circ}-\Delta i_{p}\right) /\left[H^{+}\right]^{n}$ with proper choice of $n$ gives a straight line with slope $\mathrm{K}_{\mathrm{H}^{*}}$. Figure 13 illustrates such a plot for Pu(IV)-3,4,3-LICAMS. Two straight line segments are observed. The line segment with shallow slope corresponds to the frotonation:

$$
\text { Pu(IV)-3,4,3-LICAMS }{ }^{8-}+\mathrm{H}^{+}=\mathrm{Pu}(\mathrm{IV})-3,4,3-\mathrm{HLICAMS}^{3-}
$$

The shift in $\lambda_{\max }$ in the visible spectra obtained over this $\mathrm{pH}$ range also indicate that protonation is occurring. The plot shown in Figure 13 implies that the monoprotonated Pu(IV) complex has a diffusion coefficient $30-40 \%$ smaller than that of the deprotonated Pu(IV) complex. This seems unlikely, since to a first approximation the diffusion coefficient is proportional to the volume of the complex. Therefore large changes in the diffusion coefficient would not be expected upon a single protonation. Lowering the pH further, a white flaky precipitate is formed $\left[\mathrm{Pu}(\mathrm{OH})_{4}\right.$ is green and gelatinous] and a linear decrease in current is also observed and included in Figure 13 for interest. This line segment cannot be interpreted by the same method used for the line segment of shallow slope since two species are not in equilibrium in solution as is required to use this method. Instead, 
an alternate graphical method can be used. The formation constant for such a precipitate would be

$$
K=\frac{1}{[\mathrm{Pu}(\mathrm{IV}) \mathrm{HLICAMS}]\left[\mathrm{H}^{+}\right]^{\mathrm{n}}}
$$

Therefore, a plot of $\ln \Delta i_{p}$ vs \&n $\left[H^{+}\right]$should give a line of slope $=n$. Such a plot for Pu(IV)-3,4,3-HLiCAMS is linear (correlation $=-0.9999$ ), but the slope is nonintegra] (slope $=-0.20$ ). Since this gives the change in the average number of bound protons on going from the oxidized to the reduced spec ss, it may indicate a mixture of protonated species exist in this $\mathrm{pH}$ range. It does appear that this precipitate is at least a diprotonated Pu(IV) complex. Complexes of $\mathrm{Pu}$ (IV) are prone to hydrolys is and polymerization. In addition, the bridging capabilities of catechol are well illustrated in the $\left[\mathrm{Gd}(\mathrm{III})(\mathrm{cat})_{3}\right]_{2}^{6-}$ structure, which contains two bridging catechol dianions. ${ }^{40}$ In contrast to $\mathrm{Pu}(3,4,3-$ LICAMS), the $\mathrm{Ce}(3,4,3$-LICAMS $)$ differential pulse voltamogram shows no positive shift in potential with decreasing $\mathrm{pH}$; however, it does show a decrease in pea! current. This may reflect differences in the protonation reactions in this ph range. A sumary of the protonation behavior of complexes of Pu(IV) - and Pu(III)-3,4,3-LICAMS and 3,4,3-LICAMC as determined by electrochenical methods is diagramed in Figure 14.

The implications of this study are that the complex of Pu(IV) -3,4,3LICAMS which exists at pH 7.4 (human plasma pH) is not a tetracatecholate complex. It may be a triscatecholate complex. In yivo studies of Pu(IV) removal from mice using the same concentrations of 3,4,3-LiCAMS and 3,4-LICAMS indicate that 3,4-LICAMS is more effective per functiona] catechol group. Thus $P_{b i}(V)$ does not appear to utilize the full denticity 
of the tetracatechol, 3,4,3-LICAMS. Indeed, results obtained here indicate that use of functional groups more acidic than catechol may be warranted. Development of macrochelates of the more acidic $N$-hydroxypyridinone ligand is currentiy underway.

The examination of the in vitro complexation behavior of Pu(III) and Pu(IV) by catecholate ligands was prompted by test results which indicated that synthetic catechoylamide ligands were effective in vivo sequestering agents for $\mathrm{Pu}(\mathrm{IV}) .^{58,59}$ Likewise, the study of americiumcatecholate complexation was prompted by the puzzling resu'ts of in vivo experiments in mice and dogs on americium removal by 3,4,3-LICAMS and 3,4,3-LICAMC (vide infra). ${ }^{35}$ The specificity of 3,4,3-LICAMS for metal ions of high charge to ionic radius ratios has been demonstrated by thermodynamic measurements. ${ }^{73}$ Most biologically significant metal ion are divalent ions and this study did not investigate the stability of catecholates with trivalent ions that have smaller charge to ionic radius ratios than $\mathrm{Fe}$ (III). Therefore, a study of lanthanide(III) catecholate complexes in solution was begun and continues. ${ }^{41}$ The trivalent lanthanides have been used extensively as models for triualent actinides, since size variations between homologs of the two rows are small. 37 In particular, studies with catecholate ligands have concentrated on complexation by Eu(III), the homolog of Am(III).

Originaliy it was thought that complexation of $A m(I I I)$ in vivo by cate:tolate ligands would not be of sufficient stability to remove Am(III) from test animals. Surprisingly, dogs injected with $\mathrm{Am}(\mathrm{III})$, followed 30 minutes later by injections of 3,4,3-LICAMS or 3,4,3-LICAMC, excreted $34 \%$ and $27 \%$, respectively, of the Am after seven days. (Controls excreted $11 \% . i^{35}$ The calcium, trisodium salt of diethylenetriamine pentaacetic 
acid ( $\mathrm{CaNa}_{3} \mathrm{OTPA}$ ) (the current therapeutic chelating agent for Am) is much more efficient at sequestering Am under similar conditions (83\% excreted). The plasma clearance curves for americium-treated dogs following injection of the catecholate Tigand are particularly unusual (Figure 15). ${ }^{35}$ These curves indicate that, for the dogs injected with the catechol ligand the amount of An in the plasma is increased and retained. Also, the slope of the iines following injection of LICAMS or LICAMC were similar to the slope of plasma clearance curves for untreated dogs injected with Pu(IV). The conclusion reached was that the injected catecholate induced the americium to circulate as a very stable transferrin complex, just as Pu(IV) circulates. Such protein complexes are not filtered out of the plasma. Although Am(III) is known to form complexes with transferrin, they are of limited stability, just as for the lanthanide(III) ions 5,74 discussed below. (See the decrease in concentration for the "untreated" clearance curve.) The increase of Am in the plasma following injection of catecholate ligand can be then attributed to the dynamic equilibrium that exists between extracellilar fluid and the circulation, i.e., the Am can get in the plasma, but once in, it forms a very stable complex with transferrin and does not exit.

One possible explanation is that the catecholate ligand is facilitating oxidation of $A m$ (III) to $A m$ (IV) and promoting the formation of a very stable transferrin complex similar to that of Pu(IV). Catechol has a tremendous ability to stabilize higher oxidation states of cerium and plutonium, as indicated by negative shifts of the (IV)/(III) reduction potential of 3.91 to 2.16 volts for 3,4,3-LICAMS and 3,4,3-LICAMC (Figure 10). However, the Am(IV)/(III) reduction couple is very high and requires 
an extraordinary stabilization of Am(IV) to give a complex stable in aqueous solution. Many workers have given estimates for the $\mathrm{Am}(\mathrm{IV}) /(\mathrm{III})$ reduction potential; they range between +2.0 to +2.9 V VS NHE. ${ }^{75-79}$ Since the reduction potentials of the quinone/catechol couples are near $0 \mathrm{~V}$ in strong base, this sets one limit for the oxidizing power of the Am(IV) complex if excess ligand is present.

Differential pulse voltametry of $\operatorname{Am}(3,4,3$ - LICAMS $)$ and $\operatorname{Am}(3,4,3-$ LICAMC) from -0.4 to $+0.7 \mathrm{~V}$ vs SCE at slow scan rates $(1.5 \mathrm{mV} / \mathrm{second})$ showed only electrochemistry associated with the ligand. Providing the negative shifts in the (IV)/(III) patential seen for plutonium and cerium are similar for americium, the free metal ion potential for Am(IV//(III) must be at least $+2.6 \vee$ vs NHE. Apparently oxidation of the ligand occurs at a lower potential than oxidation of the $\rho_{m}$ (III) complex. Upon lowering the pH a precipitate is formed for both $\mathrm{Am}(3,4,3-$ LICAMS) (at pH 10.0) and Am(3,4,3-LICAMC) (at pH 10.4). Results of tracer gel chromatography experiments indicate that 3,4,3-LICAMS farms a complex with Am at pH 7.4 of higher molecular weight than the Pu complex ${ }^{35}$ (Figure 16).

One method by which to determine whether or not an Am(III)catecholate complex is formed is by visible spectrascopy. Aqueous $A_{m}(I I I)$ has a large, sharp absorbance at $503 \mathrm{~nm}$ in acidic media due to a transition assigned as ${ }^{7} F_{0} \rightarrow{ }^{5} L_{6}$ as well as a broad band at 812 nm due to a ${ }^{7} F_{0} .{ }^{7} F_{6}$ transition. ${ }^{80}$ Upon complexation of $A m(I I I)$ by various ligands these bands are known to shift and change in intensity. Figures 17 and 18 illustrate the spectral changes observed in the $503 \mathrm{~nm}$ band upon complexation by 3,4,3-LICAMS and 3,4,3-LICAMC. The spectrum 
of free $A m$ (III) is of a diluted sample of stock An(III), included for crmparison (in $\mathrm{HCl}, \mathrm{pH} 2$ ). The sloping baseline in the Am-tetracatecholate spectra is due to partial oxidation of the ligand. Although the ligand solutions were prepared under argon and rigorously degassed, the transfer procedure into the cuvette causes a limited exposure to air and consequent partial oxidation of the free ligand. Nonetheless, the shift in the $503 \mathrm{~nm}$ band observed is conclusivis evidence of complexation of Am(III) by 3,4,3-LICAMS and 3,4,3-LICAMC.

It is noteworthy that the spectrum of Am(III) with 3,4,3-LICAMS and with 3,4,3-LICAMC are significant?y different. This is indicative of a different type of bonding of the two tetracatecholates with Am(III). Although it is impossible to determine the identity of the coordinating groups, the 3,4,3-LICAMC ligand does possess carboxylate groups capable of coordinating Am(III). Polycarboxylatoamines are known to bind Am(III) with high affinity. $8 T$

The results of these experiments indicate that americium is probably not present as Am(IV) in vivo Indeed, it proves that 3,4,3-LICAMS and 3,4,3-LICAMC form complexes with Am(III) of undetermined stoichiometry and stability. The solution chemistry of Eu(III), a homolog of Am(III), with 3,4,3-LICAMS and several monomeric catechols [catechol, Tiron and $\mathrm{N}, \mathrm{N}-$-dimethyl-2,3-dihydroxy-5-sulfobenzamide (DMBS), which is structurally the same as the CAM moieties of 3,4,3-LICAMS] have been examined ill order to model the behavior of $\mathrm{Am}$ (III). ${ }^{41}$ Below $\mathrm{pH} 9$ catechol and Tiron form 1:1 Eu complexes, while DMBS forms a 3:2 (1 igand:metal) complex, regardless of ligand excess. Surprisingly, 3,4,3-LICAMS with its four pairs of phenolic groups also forms only a $3: 2$ catechoyl arm: Eu complex, in which three $\mathrm{OH}$ groups per ligand were deprotonated for each metal ion bound. 
A Job's plot 82 of the Eu(III)-DMSS complex is shown in Figure 19, where the molar ratios of ligand to EU(III) were varied over a wide range while maintaining [EU(III)] + [1igand] constant. The maxima in the piot gives the 3:2 stoichiometry of the Eu(III)-DMBS complex in solution.

The Eu-catechol complex is very weak, and above $\mathrm{pH} 7$ excess caterhol was not able to prevent precipitation of $\mathrm{Eu}(\mathrm{cat}) \mathrm{OH} \cdot 4 \mathrm{H}_{2} \mathrm{O}$. The Eu complexes with the sulfonated catecholates are more stable, and above $\mathrm{pH} 7$ formation of insoluble hydrolys is products was prevented. For Eu-Tiron, $\log K_{f}$ is 13.2, about two $\log$ units greater than for catechol, in accord with its greater acidity.

Titrations of $E U(I I I)$ with $3,4,3$-LICAMS indicate that a complex is formed whereby 1.5 catechol arms bind Eu(III) at pH 5.5. At higher pH values some hydroxide also appears to be involved in coordination and equilibrium is achieved only slowly. It seems likely that the Am(III) (3,4,3-LICAMS) complex is similar.

Recently it has been established that monocatecholates can act as the necessary synergistic anion required in the binding of $\mathrm{Fe}$ (III) to transferrin, al though the catecholates are not themodynamically favored over the natural synergistic anion carbonate. 83 This does however establish the existence of ternary catechol-Fe([II)-transferrin complexes. One possible explanation for the unusual plasma clearance curves of the $\operatorname{Am}(3,4,3-\operatorname{LICAMS}$ and $\operatorname{Am}(3,4,3-\operatorname{LICAMC})$ is the existence of a ternary complex of tetracatecholate-Am-transferrin.

\section{Summary}

The synthesis of a series of tetracatecholate ligands designed to be specific for Pu(IV) and other actinide(IV) ions has been achieved. 
Al though these compounds are very effective as in vivo plutonium removal agents, potentiometric and voltametric data indicate that at neutral $\mathrm{pH}$ full complexation of the Pu(IV) ion by all four catecholate groups does not occur. This implies more acidic chelating groups must be incorporated in the next cycle of ligand design, synthesis and evaluation for chelating agents specific for Pu(IV).

Spectroscopic results indicate that the tetracatecholates, 3,4,3LICAMS and 3,4,3-LICAMC, complex Am(III). The Am\{IV)/(III)-catecholate couple (where catecholate $=3,4,3$-LICAMS or 3,4,3-LICAMC) is not observed, but may not be observable due to the large currents associated with ligand oxidation. However, within the potential range where ligand oxidation does not occur, these experiments indicate that the reduction potential of free $A m$ (IV)/(III) is probabiy $\geq+2.6 \mathrm{~V}$ vs NHE or higher. Proof of the complexation of americium in the trivalent oxidation state by 3,4,3-LICAMS and 3,4,3-LICAMC el iminates the possibility of tetracatecholates stabilizing $\mathrm{Am}(\mathrm{IV})$ in vivo.

\section{Acknowledgments}

We acknowledge the contribution to this paper by Or. Zhu, Daohong and we thank her for allowing the citation of some of her unpublished work. We thank our other co-workers, past and present, whose contributions are cited in the references. This work was supported by the Director, Office of Energy Research, Office of Basic Energy Sciences, Chemical Sciences Division of the U.S. Department of Energy under Contract Number DE-AC03-765F00098. 
References

1. Blomeka, J. 0.; Nichols, J. P.; McLain, W. C. Physics Today, August $1973,26,36-42$.

2. Kube, A. S.; Rose, D. J. Science, 1973, 182, 1205-11.

3. Bienvenu, P.; Nofre, C.; Cier, A. C. R. Acad. Sci., 1963, 256, 1043-4.

4. Stannard, J. N. "The Health Effects of Plutonium and Radium"; Jee, H. S. S., Ed.; J. H. Press: Salt Lake City, 1976; pp 362-72.

5. Ourbin, P. W. "Handbook of Experimental Pharamacology, Vol. 36: Uranium, Plutonium, Transplutonic Elements"; Hodge, H. C.; Stannard, J. N.; Hursh, J. B., Eds.; Springer-Vergag: New York, 1973; pp 739-896.

6. Denham, D. H. Health Physics, 1969, 16, 475-87.

7. 8air, J. C.; Thompson, R. C. Science, 1974, 183, 715-22.

8. Jones, M. M.; Pratt, T. H. J. Chem. Ed., 1976, 53, 342-7.

9. Ourbin, P. W. Health Physics, 1975, 29, 495-510.

10. International Commission on Radiological Protection, Publication 19: "The Metabolism of Compounds of Plutonium and Other Actinides"; Pergamon Press: New York, 1972.

11. Rundo, J.; Starzyk, P. M.; Sedlet, J.; Larsen, R. P.; Oldham, R. 0.; Robinson, J. J. "Diagnosis and Treatment of Incorporated Radionuc 7 ides"; International Atomic Energy Agency: Vienna, 1976; pp 15-23.

12. Vaughan, J.; Bleany, B.; Tij:?ar, D. M. "Handbook of Experimental Phamacology, Vol. 36: Lranium, Plutonium, Transplutonic Elements"; Hodge, H. C.; Stannard, J. N.; Hursh, J. B., Eds.; Soringer-Verlag: New York, 1973; pp 349-502 
13. Catsch, A. "Diagnos is and Treatment of Incorporated Radionuclides"; International Atomic Energy Agency: Vienna, 1976; pp 295-305.

14. Smith, V. H. Heaith Physics, 1972, 22, 765-78.

15. Catsch, A.; Harmuth-Hoene, A-E. Biochemical Pharmacology, 1975 , 24, 1557-62.

16. Pachauri, O. P.; Tandon, J. P. J. Inorg. Nucl. Chem., 1975, 37, 2321-3.

17. Pachauri, O. P.; Tandon, J. P. Indian J. Chem., 1977, 15A, 57-8.

18. Pachauri, 0. P.; Tandon, J. P. J. Gen. Chem. USSR (Engl. Transl.), 1977, 47, 398-401; Zh. Obshch. Khim., 1977, 47, 433-6.

19. Carey, G. H.; Marte11, A. E. J. An. Chem. Soc., 1968, 90, 32-8.

20. Bogucki, R. F.; Marte11, A. E. J. Am. Chem. Soc., 1958, 80, 4170-4.

21. Fried, A. R.; Martell, A. E. J. Am. Chem. Soc., 1971, 93, 4695-700.

22. Grimes, J.H. "Diagnosis and Treatment of Incorporated Radionuclides": International Atomic Energy Agency: Vienna, 1976; pF. $419-60$.

23. Cohen, N.; Guilmette, R. Bioinorganic Chem., 1975, $\underline{5}, 203-10$. 24. Seven, M. J. "Metal-Binding in Medicine"; Seven, M. J.; Johnson, L. A., Eds.; J. B. Lippincott: Philadeiphia, 1960; pp 95-103.

25. Foreman, H.; Nigrovic, V. "Diagnosis and Treatment of Deposited Radionuclides"; Kornberg, H. A.; Norwood, W. D., Eds.; Excerpta Media Foundation: Ams terdam, 1968; pp 419-23.

26. Planas-Bohne, F.; Lohbreier, J. "Diagnosis and Treatment of Incorporated Radionuclides"; International Atomic Energy Rgency; Vienna, 1976; pp 505-15. 
27. Taylor, D. M. "Handbook of Experimental Pharmacology, Voi. 36: Uranium, Plutonium, Transplutonic Elements"; Hodge, H. C.; Stannard, J. N.; Hursh, J. B., Eds.; Springer-Verlag: New york, 1973; pp 323-47.

28. Bullman, R. A. Structure and Bonding, 197i , 34, 39-77.

29. Taylor, D. M. Health Physics, 1972, 22, 575-81.

30. Popplewe11, D. S. "Diagnosis and Treatment of Incorporated Radionuclides"; International Atomic Energy Agency: Vienna, 1976; pp 25-34.

31. "Microbial Iron Metabolism"; Neilands, J. B., Ed.: Academic Press: New York, 1974.

32. Raymond, K. N. "Advances in Chemistry Series, No. 162: Bioinorganic Chemistry - II"; Raymond, K. N., Ed.; American Chemical Society: Washington, D.C., 1977; pp 33-54.

33. Raymond, K. N.; Carrano, C. J. Acc. Chem. Res., 1979, 12, 183-90. 34. Huheey, J. E. "Inorganic Chemistry: Principles of Structure and Reactivity": Harper and Rowe: New York, 1972; pp 418-22.

35. Lloyd, R. D.; Bruenger, F. W.; Atherton, D. R.; Jones, C. W.; Taylor, G. N.; Stevens, W.; Mays, C. W.; Durbin, P. W.; Jeung, N.; Jmes, E. S.; KappeT, M. J.; Raymond, K. N.; Wei $\iota^{\top}$. F. L., manuscipt in preparation.

36. Kappel, M. J.; Nitsche, H.; Raymond, K. N., manuscript in preparation.

37. Shannon, R. D. Acta. Crystallogr., Sect. A, 1976, A32, 751-67.

38. Raymond, K. N.; Smith, W. L. Structure and Bonding (BerIin), 1981 , 43, $159-86$.

39. Raymond, K. N.; Smith, W. L.; Weit1, F. L.; Durbin, P. H.; Jones, E. S.; Abu-Dari, K.; Sofen, S. R.; Cooper, S. R. Am. Chem. Soc. Symp. Ser., 1981 131, 143-172. 
40. Freeman, G. E., work in progress.

41. Zhu, D.; Kappel, M. J.; Raymond, K. N., manuscript in preparation.

42. Casellato, U.; Vidali, M.; Vigato, P. A. Inorg. Chim. Acta, 1976 , 18, $77-112$.

43. Moseley, P. T. "MTP Int. Rev. Sci.: Inorg. Chem., Ser. Two";

Bagna11, K. W., Ed.; Butterworth: London, 1975; Vol. 7, pp 65-110.

44. Hoard, J. L.; Silverton, J. V. Inorg. Chem., 1963, 2, 235-43.

45. Burdett, J. K.; Hoffmann, R.; Fay, R. C. Inorg. Chem., 1978, 17, 2553-68.

46. B1 ight, D. G.; Kepert, D. L. Inorg. Chem., 1972, 11, 1556-61.

47. Porai-Koshits, M. A.; Aslanov, L. A. J. Struct. Chem. USSR (Engl. Trans 1.), $\lambda(272,13,244-53$; Zh. Strukt. Khim., 1972, 13, 266-76.

48. Muetterties, E. L.; Guggenberger, L. J. J. Am. Chem. Soc., 1974, 96, 1748-56.

49. Kepert, D. L. Prog. Inorg. Chem., 1978, 24, 179-249.

50. Sofen, S. R.; Abu-Dari, K.; Freyberg, D. P.; Raymond K. N. U. Am. Chem. Soc., 1978, 100,7882--.

51. Sofen, S. R.; Cooper, S. R.; Raymond, K. N. Inory. Chem., 1979, 18, 1611-16.

52. Latimer, W. M. "Oxidation States of the Elements and Their Potertials in Aqueous Solution", 2nd ed.; Prentice-Hall: Englewood Cliffs, New Jersey, 1962; p 294.

53. Ho, T.-L.; Ha11, T. W.; Wong, C. M. Chem. Ind. (London), 1972, 729-30.

54. Raymond, K. N.; Isied, S. S.; Brown, L. D.; Fronczek, F. F.; Nibert, J. H. J. Am. Chem. Soc., 1976, 98, 1767-74. 
55. Cooper, S. R.; Koh, T. B.; Raymond, K. N. J. Am. Chem. Soc., 1982, $104,5092-5102$.

56. Magers, K. D.; Smith, C. G.; Sawyer, D. T. Inorg. Chem., 1978, 17, 515-23.

57. Meites, L. "Polarographic Techniques"; Wiley: Mew York, 1965; P 279.

58. Durbin, P. W.; Jones, E. S.; Raymond, K. N.; Weitl, F. L. Radiat. Res, $1980,81,170-87$.

59. Weiti, F. L.; Raymond, K. N.; Durbin, P. W. J. Med. Chem., 1981, 24, 203-06.

60. Harris, W. R.; Carrano, C. J.; Cooper, S. R.; Sofen, S. R.; Avdeef, A.; McArdle, J. V.; Raymond, K. N. J. Am. Chem. Soc., 1979, 101 , 6097 .

61. Borgias, B.; Cooper, S. Koh, Y.; Raymond, K., submitted to J. Am. Chem. Soc.

62. Bard, A. J.; Faulkner, L. R. "Electrachemical Methods"; J. Wiley and Sons: New York, 1980; back cover.

63. Meites, L. "Polarographic Techniques", Second Edition; J. Wiley and Sons: New York, 1965; 203-301.

64. Osteryoung, R. A.; Osteryoung, J. Phil. Trans. R. Lond., 1987, A302, $315-26$.

65. Connick, R. E.; Mcley, H. H. 3. Am. Chem. Soc., 1951, 73, 1798.

66. Weitl, F. L.; Raymond, K. N.; Smith, W. L.; Howard, T. R. J. Am. Chem. Soc., 1978, 100, 1170.

67. Weitl, F. L.; Raymond, K. N. J. Am. Chem. Soc., 1980, 102, 2289.

68. Harris, W. R.; Raymond, K. N.; Weitl, F. L. J. Am. Chem. Soc., 1981, 103, 2667-75. 
69. Pecoraro, V.; Scarrow, R.; Kappe1, M.; Raymond, K., manuscript in preparation.

70. Kappel, M. J., unpublished results.

71. Keller, H. E.; Osteryoung, R. A. Anal. Chem., $\lambda(27 h, 43,342-48$.

72. Schwarzenbach, G.; Schwarzenbach, K. Hely. Chim. Acta, 1963, 46, 1390.

73. Kappel, M. J.; Raymond, K. N. Inorg. Chem., 1982, 21, 3437.

74. Luk, C. K. Biochemistry, 1971, 10, 2838.

75. Morss, L. R.; Fuger, J. J. Inorg. Nucl. Chem., 1981, 43, 2059.

76. Cunningham, 8. B. Ann. Rev. Nuc1. Sci., 1964, 14, 323.

77. Fugent, L. J.; Baybarz, R. O.; Burnett, J. L.; Ryan, J. L. J. Phys. Chem., 1973, 77, 1528.

78. Hobart, D. E.; Samhoun, K.; Peterson, J. R. Radiochimica Acta, 1982, 31. 139 .

79. Penneman, R. A.; Coleman, J. S.; Keenan, T. K. 3. Inorg. Nucl. Chem., $196], 17,138$.

80. Shitoh, M1.; Givon, M.; Marcus, Y. 3. Inorg. Nucl. Chem., 1969, 31, 1807.

81. Site, A. D.; Baybarz, R. D. J. Inorg. Nuel. Chem., 1969, 3I, 2201.

82. Angelici, R. J. "Synthes, s and Technique in Inorganic Chemistry";

W. B. Saunders Co.: Philadelphia, 1969; pp 99-103.

83. Loomis, L., persoral communication. 
Figure Captions

Figure 1. A tabulation of some of the chenical and biological similarities of Pu(IV) and Fe(III).

Figure 2. The siderophores enterobactin and desferrioxamine $B$ (DFO).

Figure 3. Eight-coordinate polyhedra. The principal axes are vertical. Edge labels are taken from Refs. 44 and 47.

Figure 4. The $\left[M_{(}\left(\mathrm{O}_{2} \mathrm{C}_{6} \mathrm{H}_{4}\right)_{4}\right]^{\mathrm{n}-}$ anion ( $\mathrm{n}=4$ when $\mathrm{M}=\mathrm{Hf}, \mathrm{Ce}$, Th and $U_{i} n=5$ when $M=$ Gd) viewed along the mirror plane with the $\overline{4}$ axis vertical.

Figure 5. A schematic structure of a Pu(IV)-tetracatechoylanide complex.

Figure 6. Structures of 3,4,3-LICAMS and 3,4,3-LICAMC.

Figure $7 . \quad$ The $\left[\mathrm{Ed}\left(\mathrm{O}_{2} \mathrm{C}_{6} \mathrm{H}_{4}\right)_{3}\right]_{2}^{6-}$ anion.

Figure 8. Plot of the dependence of $E_{1 / 2}$ an total catechol concentration $\left(L_{T}=12.4\right.$ to $\left.1000.0 \mathrm{mM}\right)$ for the $\mathrm{Ce}$ (IV)/Ce(III) couple. 
Figure 9. Plot of the dependence of $E_{1 / 2}$ on total catechol concentration $\left(L_{T}=9.0\right.$ to $\left.32.0 \mathrm{mN}\right)$ for the $\mathrm{PU}(\mathrm{IV}) / \mathrm{PU}(\mathrm{III})$ couple.

Figure 10. A tabulation of the redox potential shifts for the IV/III couple of PU and he for several catechol 1 igands.

Figure 11. Differential pulse voltammograms of Pu(3,4,3-LICAMS) as a function of $\mathrm{pH}(\mathrm{pH} 10.59,10.12,9.90,9.68,9.36$, $8.79,7.39,6.85)$.

Figure 12. A plot of the variation of $\mathrm{E}_{1 / 2}$ with $\mathrm{pH}$ for $\mathrm{Pu}(3,4,3$-LICAMS $)$.

Figure 13. Plots of the variation of peak current with $\mathrm{pH}$ for $\operatorname{Pu}(3,4,3-$ LICAMS $)$.

Figure 14. Sumary of the Pu polycatecholate equilibria as determined by electrochemistry. The species related by redox or equilibria reactions are shown.

Figure 15. $\quad{ }^{241}$ Am in plasma of young adult beagles injected with 30 umol/kg of ligand 30 minutes after nuclide administration (first 3 hours).

Figure 16. Elution profiles on Sephadex G-25 gel of Pu and Am in a 3,4,3-LiCAMS solution. 
Figure 17. Visible spectra of free $A m(I I I)(0.20 \mathrm{~mm}, \mathrm{pH} 2)$, $\operatorname{Am}(3,4,3$-LICAMS $(0.12 \mathrm{mM}, \mathrm{pH} 13), \operatorname{Am}(3,4,3-\operatorname{LiCAMC})$ (0.12 mH, pH 13).

Figure 18. A summary of Am(III) spectra which shows the effect of catechol complexation compared to the free aquo complex.

Figure 19. A Job's plot (absorbance as a function of ligand/metal mo: - ratio) of EU(III) and N,N-dimethyl-2,3-dihydroxy5-sul fobenzamide (DMBS). 
SimiLARITIES OF Pu ${ }^{4+}$ AND FE ${ }^{3+}$

$$
\begin{aligned}
& \frac{\text { ChARGE }}{\text { IONIC RADIUS }} \quad \mathrm{Pu}^{4+\frac{4}{.96}}=4.2 \quad \mathrm{FE}^{3+} \frac{3}{.65}=4.6 \\
& \begin{array}{ll}
\mathrm{FE}\left(\mathrm{OH}_{3}\right) \Longrightarrow \mathrm{FE}^{3+}+3 \mathrm{OH}^{-} & \mathrm{K}=10^{-38} \\
\mathrm{FE}^{3+}+\mathrm{H}_{2} \mathrm{O} \rightleftharpoons \mathrm{FE}(\mathrm{OH})^{2+}+\mathrm{H}^{+} & \mathrm{K}=0.0009
\end{array} \\
& \mathrm{Pu}(\mathrm{OH})_{4} \rightleftharpoons \mathrm{Pu}^{4+}+40 \mathrm{H}^{-} \quad \mathrm{K} \approx 10^{-55} \\
& \left.\mathrm{Pu}^{4+}+\mathrm{H}_{2} \mathrm{O} \rightleftharpoons \mathrm{Pu}(\mathrm{OH})^{3+}+\mathrm{H}^{+} \quad \mathrm{K}=0.031 \text { ( IN HCLO }{ }_{4}\right)
\end{aligned}
$$

$\mathrm{Pu}^{4+}$ TRANSPORTED in bloOd PLASMa OF Mammals as a COMPLEX OF transferrin (the normal transport agent of $\mathrm{FE}^{3+}$ ), The Pu ${ }^{4+}$ binds at same site as $\mathrm{FE}^{3+}$. 

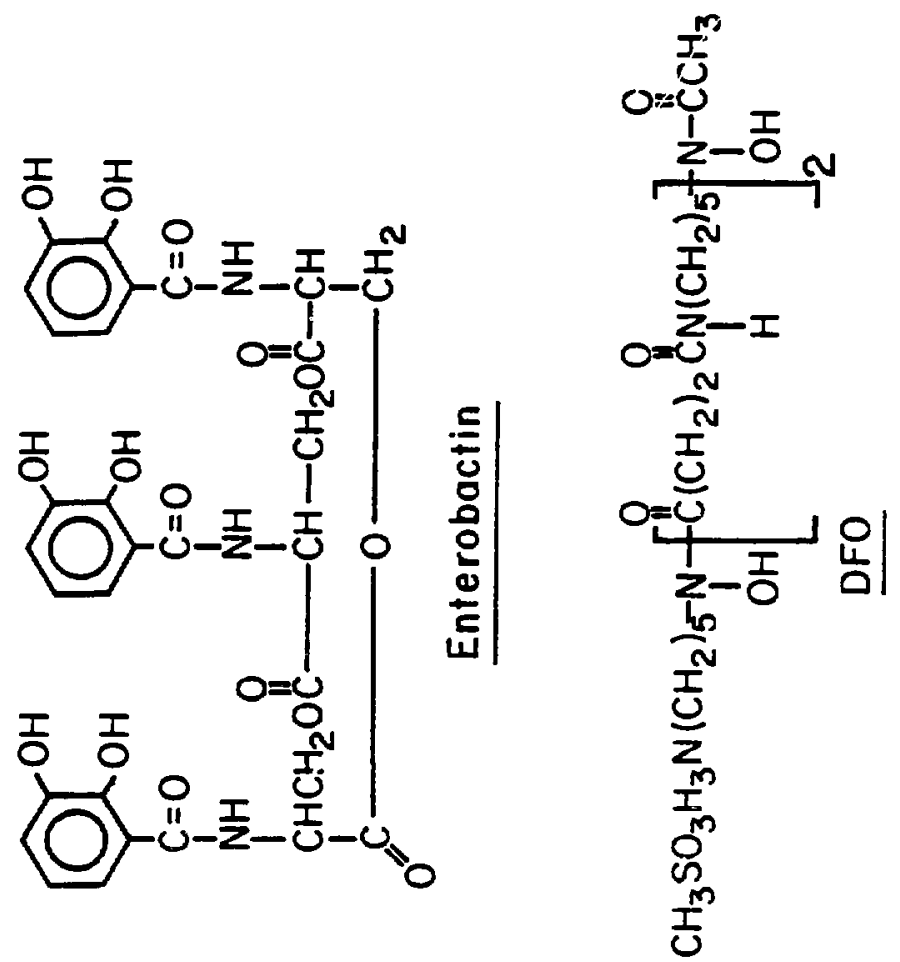

号 

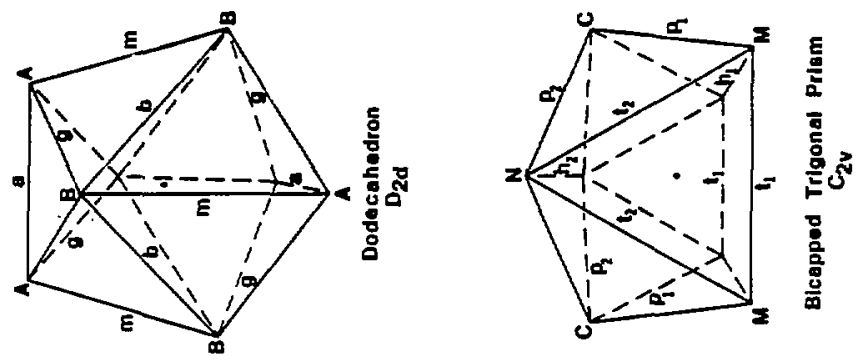

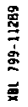
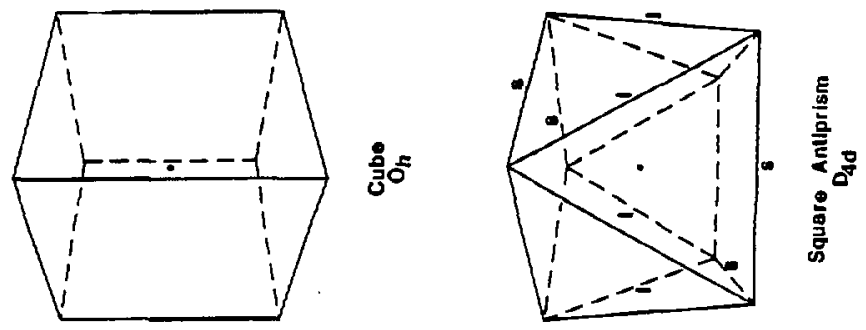

$m$
0
$\frac{3}{3}$
$\frac{1}{4}$ 


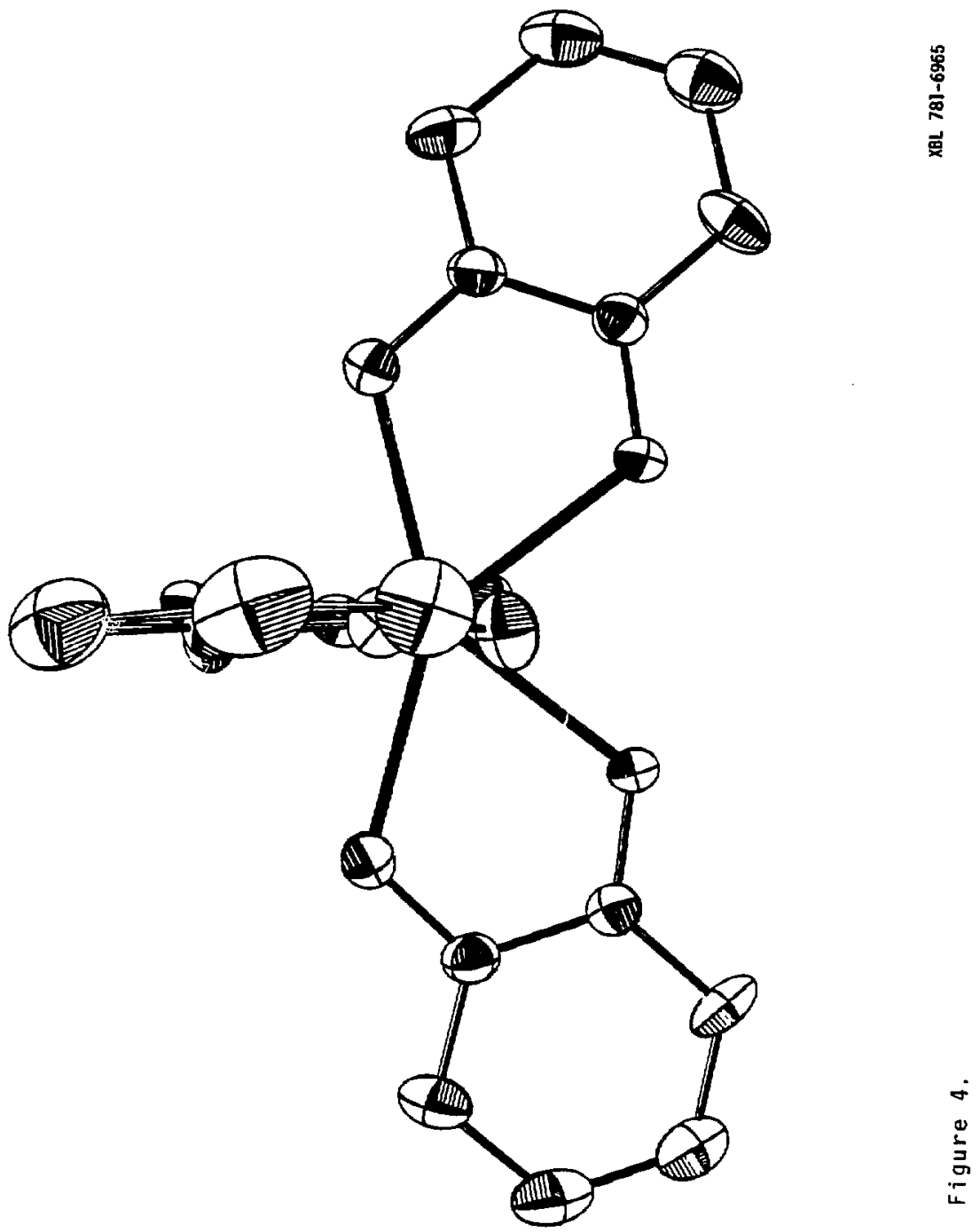




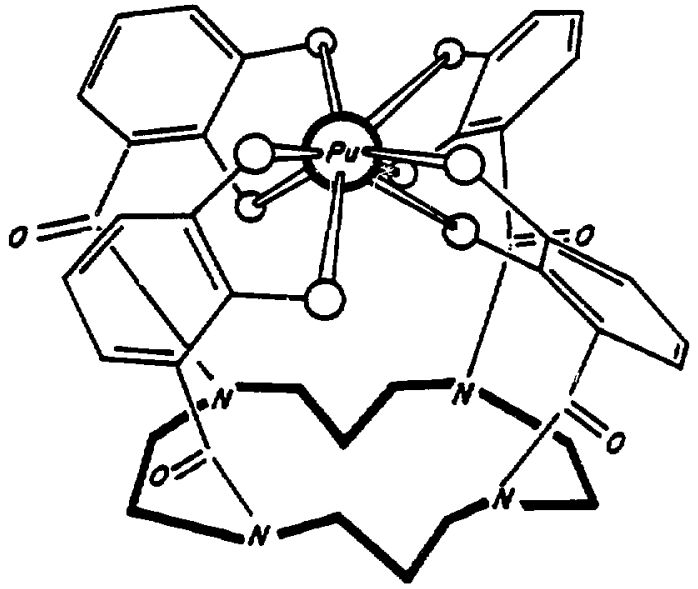

XBL $772-7549$

Figure 5. 
CATECHOYLAMIDE LIGANDS
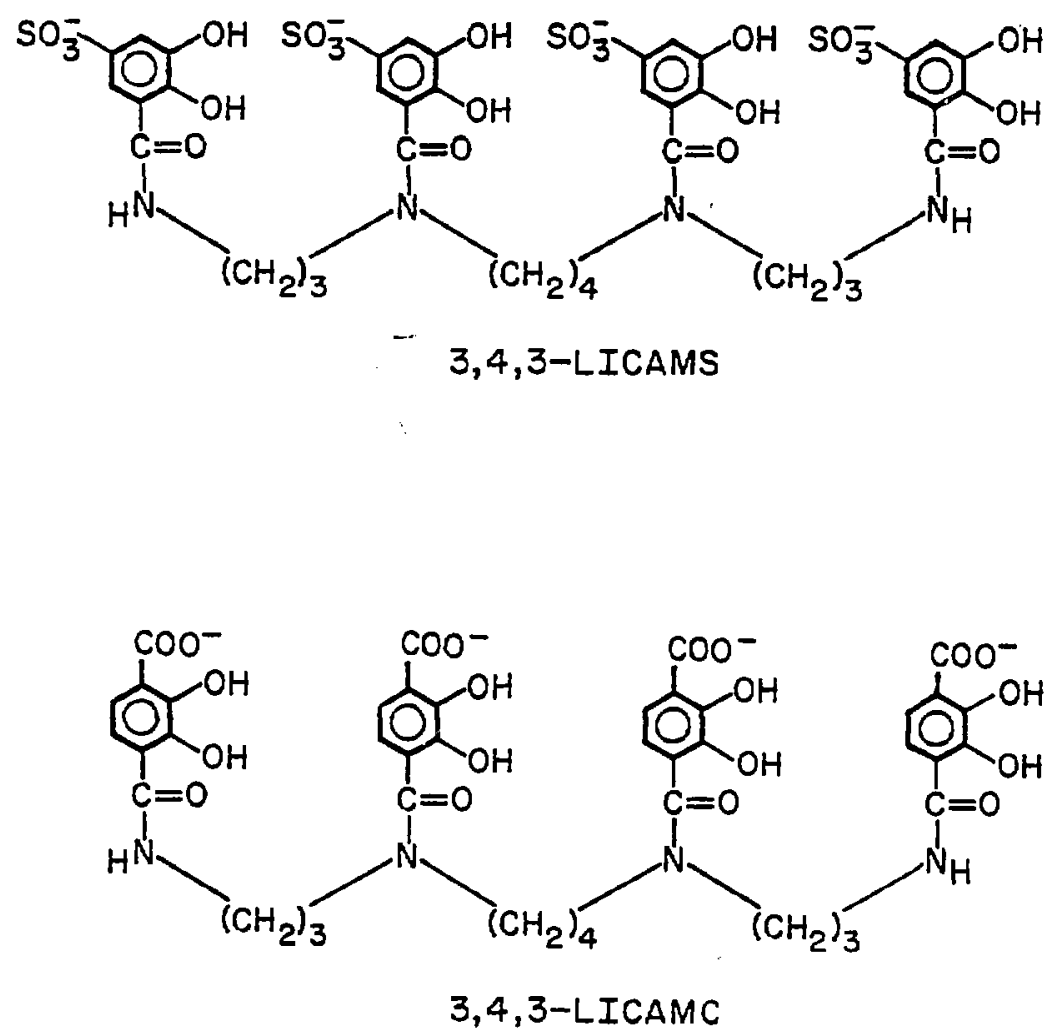

XBL $833-8708$

Figure 6 . 


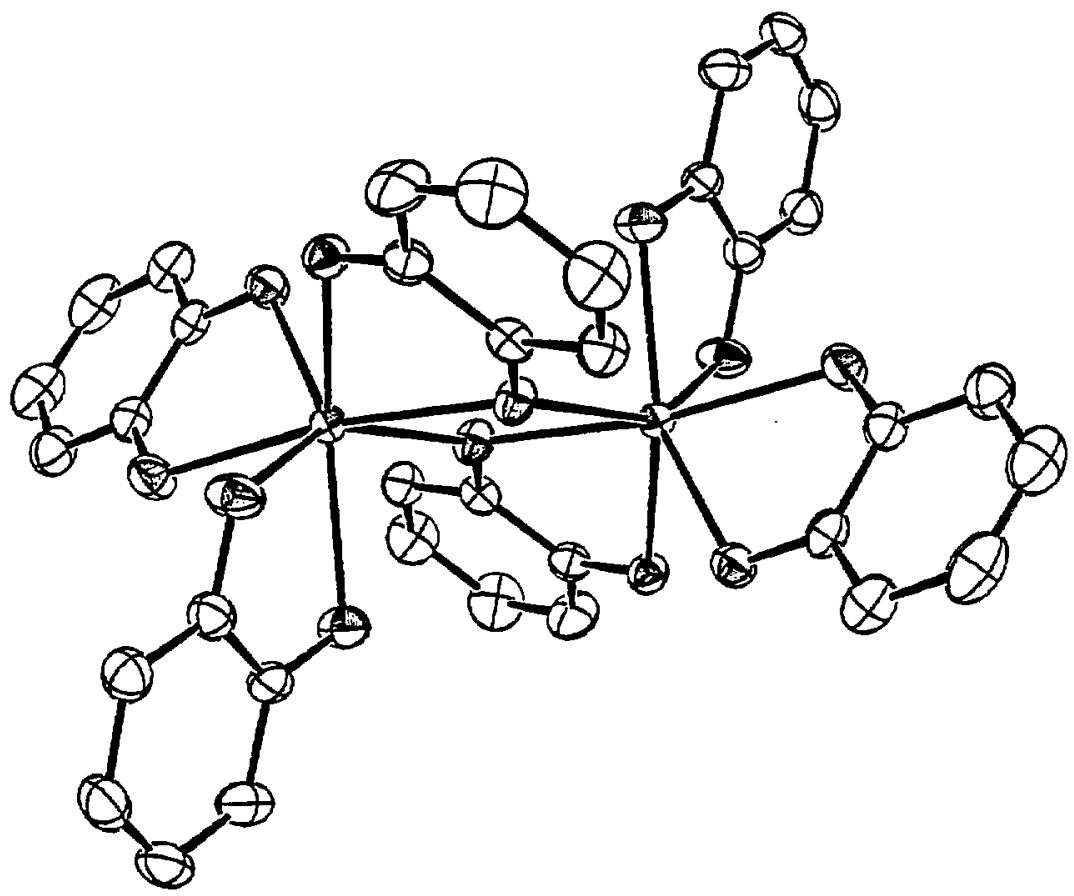

XBL 838-504

Figure 7. 


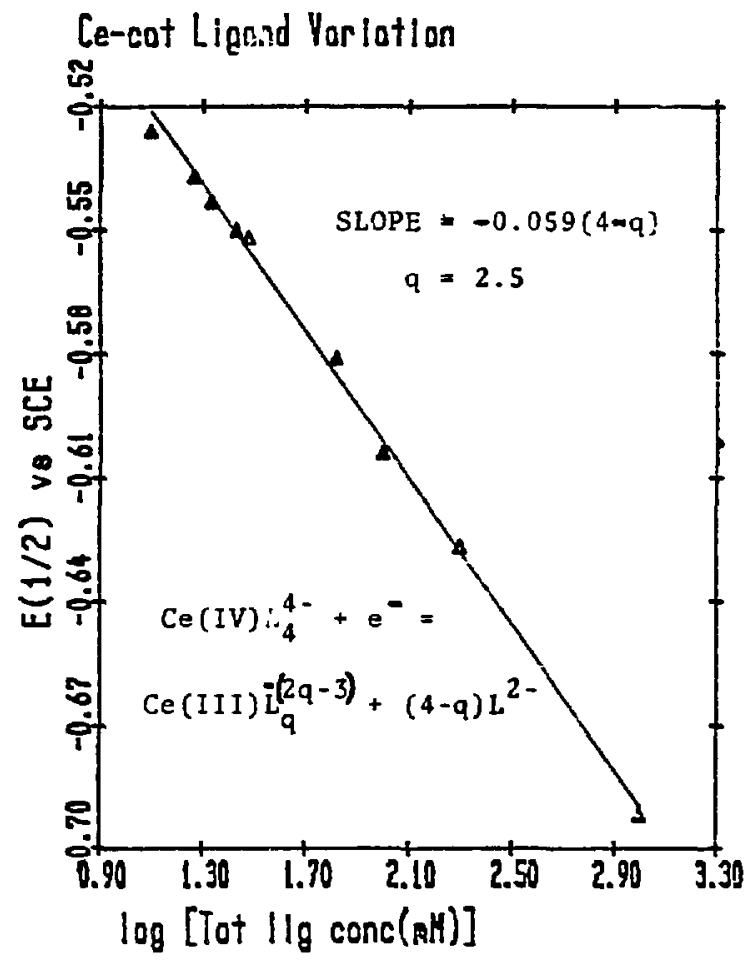

$X 8 L$ 837-10656

Figure 8. 


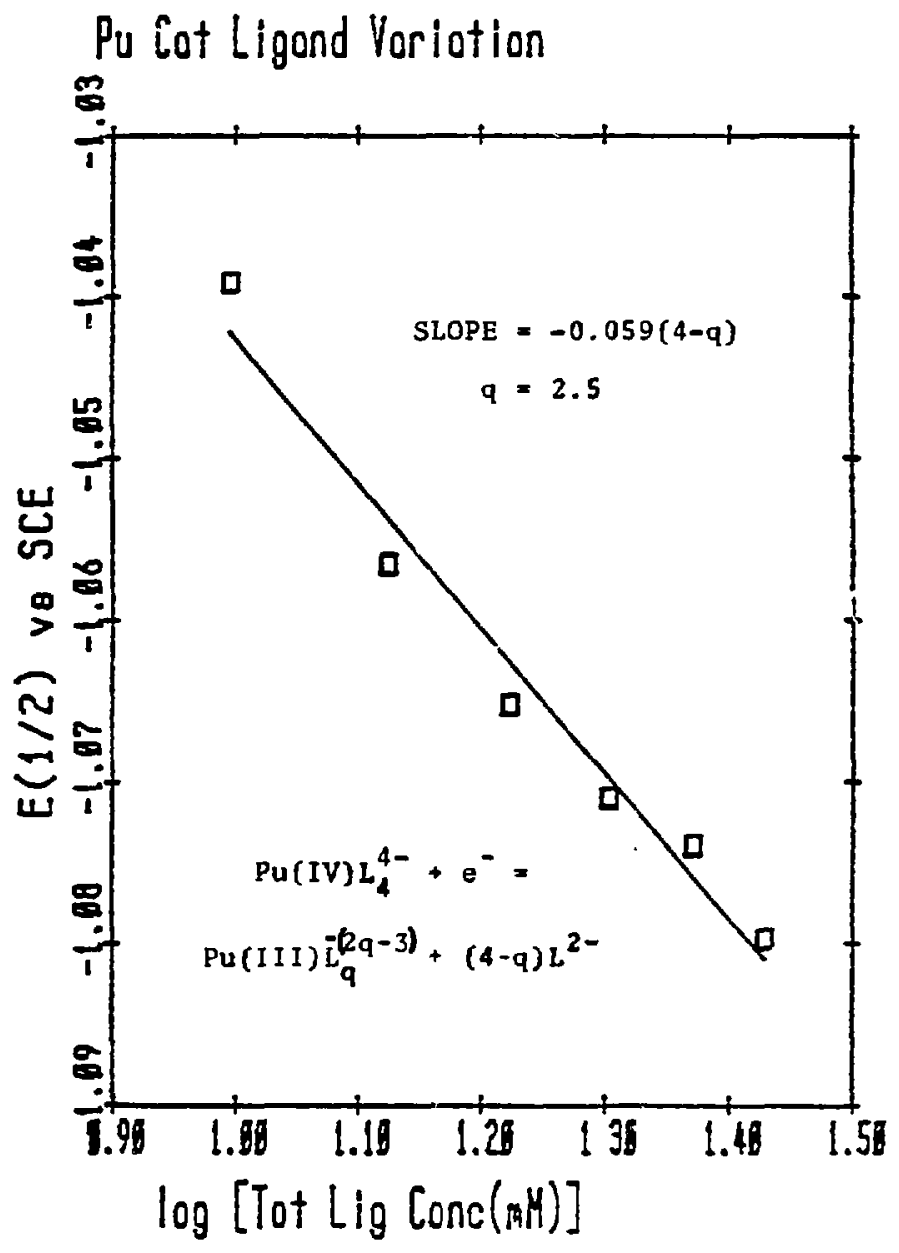

XBL $837-10655$

Figure 9. 
Potential Shifts of Catecholate-bound Pu and $\mathrm{Ce}$

\begin{tabular}{|c|c|c|}
\hline Ligand & $\begin{array}{l}\text { Shift of } \\
\text { Ce(IV)/Ce(III) } \\
\text { (Volts) } \\
\end{array}$ & $\begin{array}{c}\text { Shift of } \\
\text { Pu(IV)/Pu(III) } \\
\text { (Volts) } \\
\end{array}$ \\
\hline Catechol & -2.00 & -1.82 \\
\hline Tiron ${ }^{c}$ & -1.97 & -2.07 \\
\hline $3,4,3$-L I CAMS & -2.11 & -1.91 \\
\hline $3,4,3-L I$ CAMC & -2.16 & -2.03 \\
\hline
\end{tabular}

Potential in $1 \mathrm{M} \mathrm{HClO} 4$ vs. NHE:

$\begin{array}{ll}\text { a. } & \text { Ce(IV) }+e^{-}=\operatorname{Ce}(I I I)+1.7 \text { Volts } \\ \text { b. } & \text { Pu(IV) }+e^{-}=\operatorname{Pu}(I I I)+0.98 \text { Volts } \\ \text { c. Irreverible } & \end{array}$

Figur: 10 


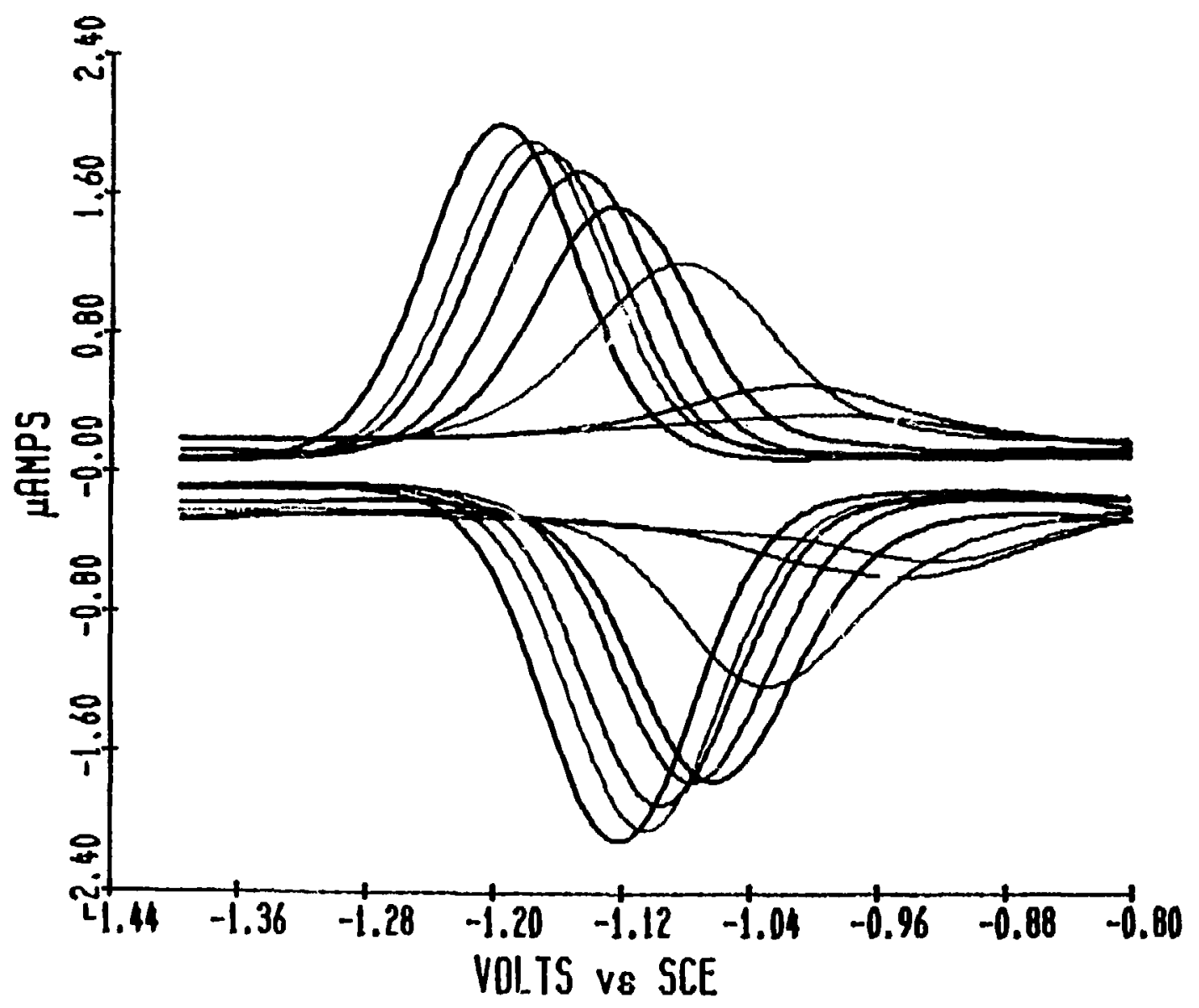




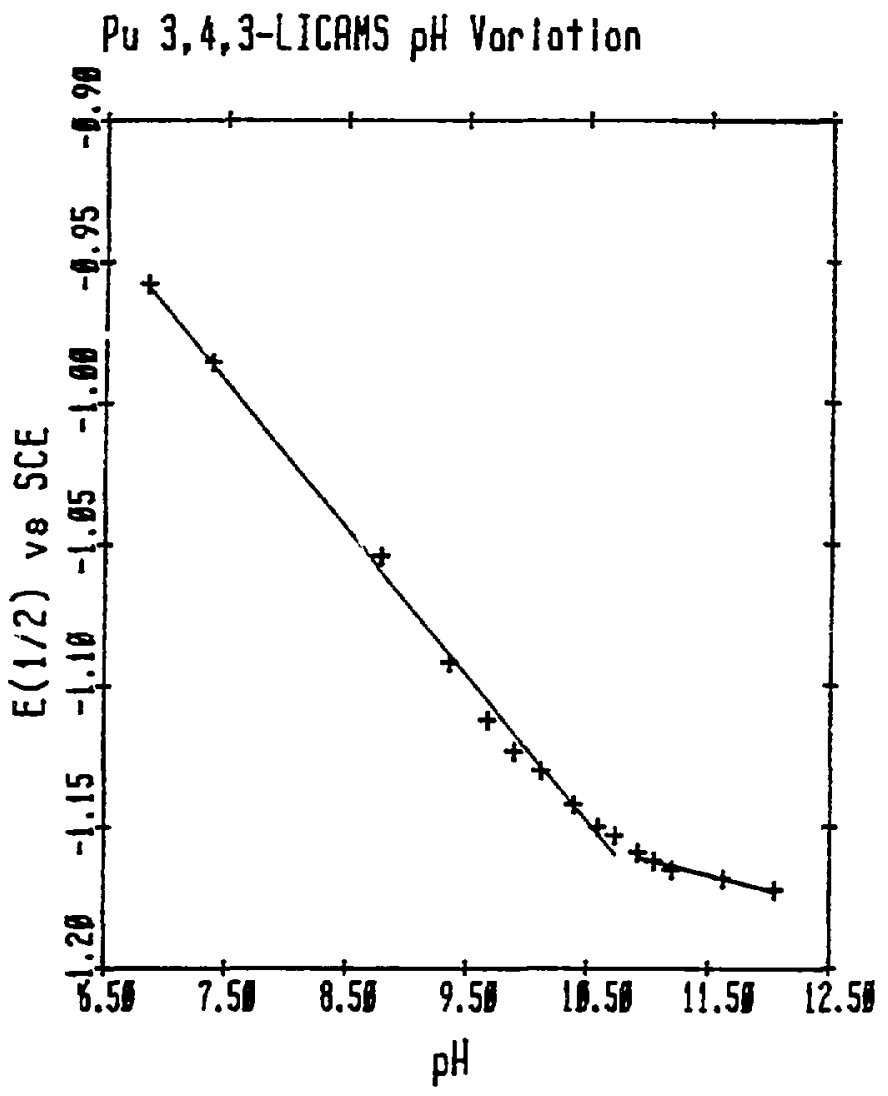

XBL $833-8710$

Figure 12 . 


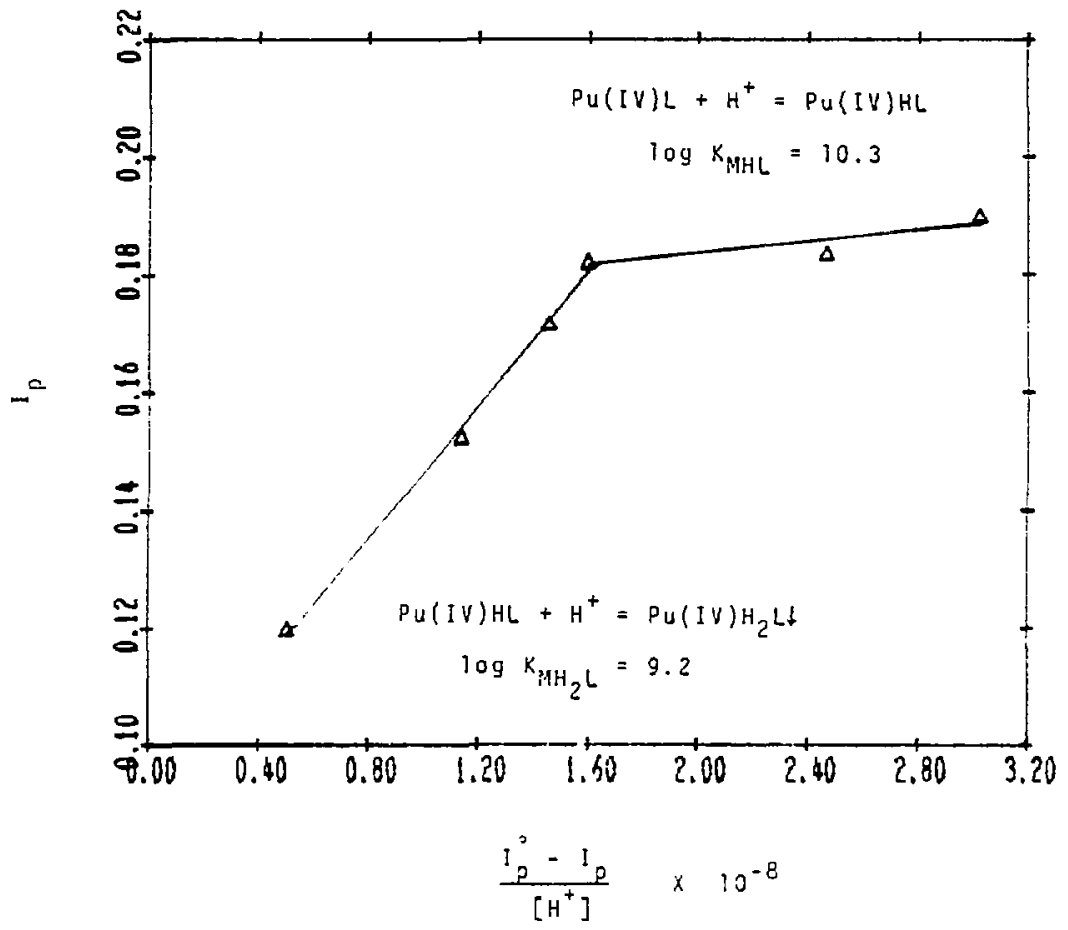

XBL 833-8712

Figure 13. 


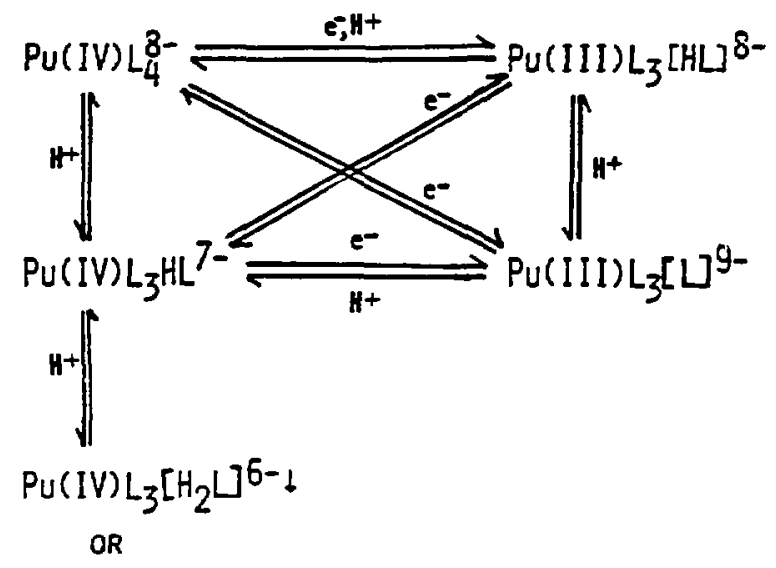

Pú(IV) L HLHLL $_{2}$ G-

$L=$ BOUND LIGAND ARM $[L]=$ FREE LIGAND ARM
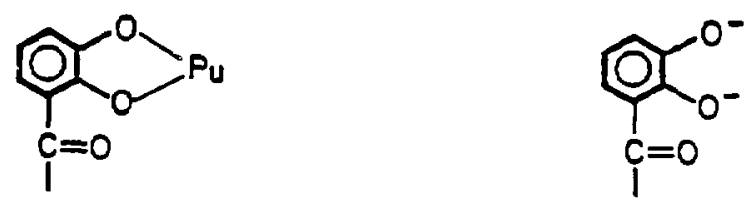

Figure 14. 


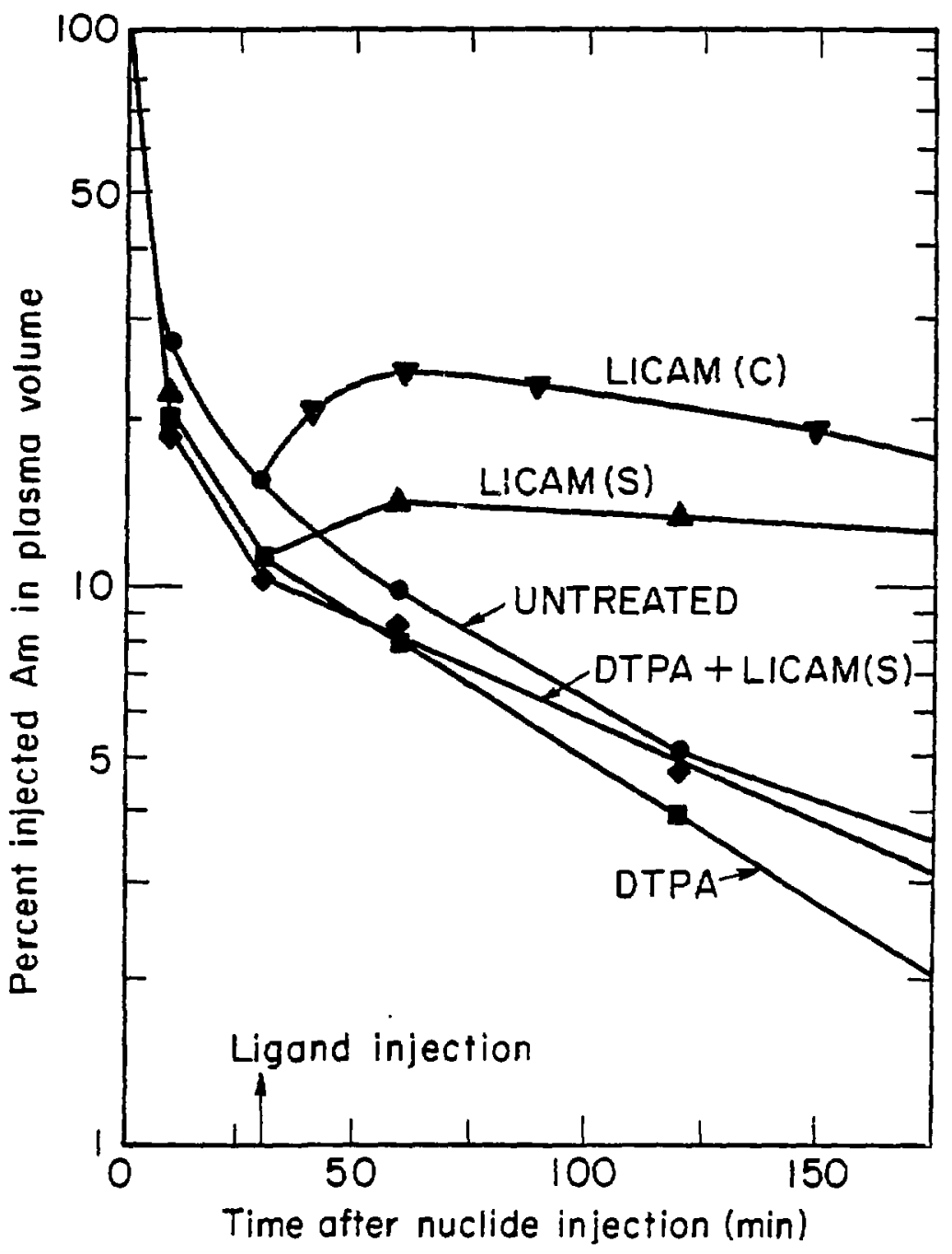

$X B L 834-3695$

Figure 15. 


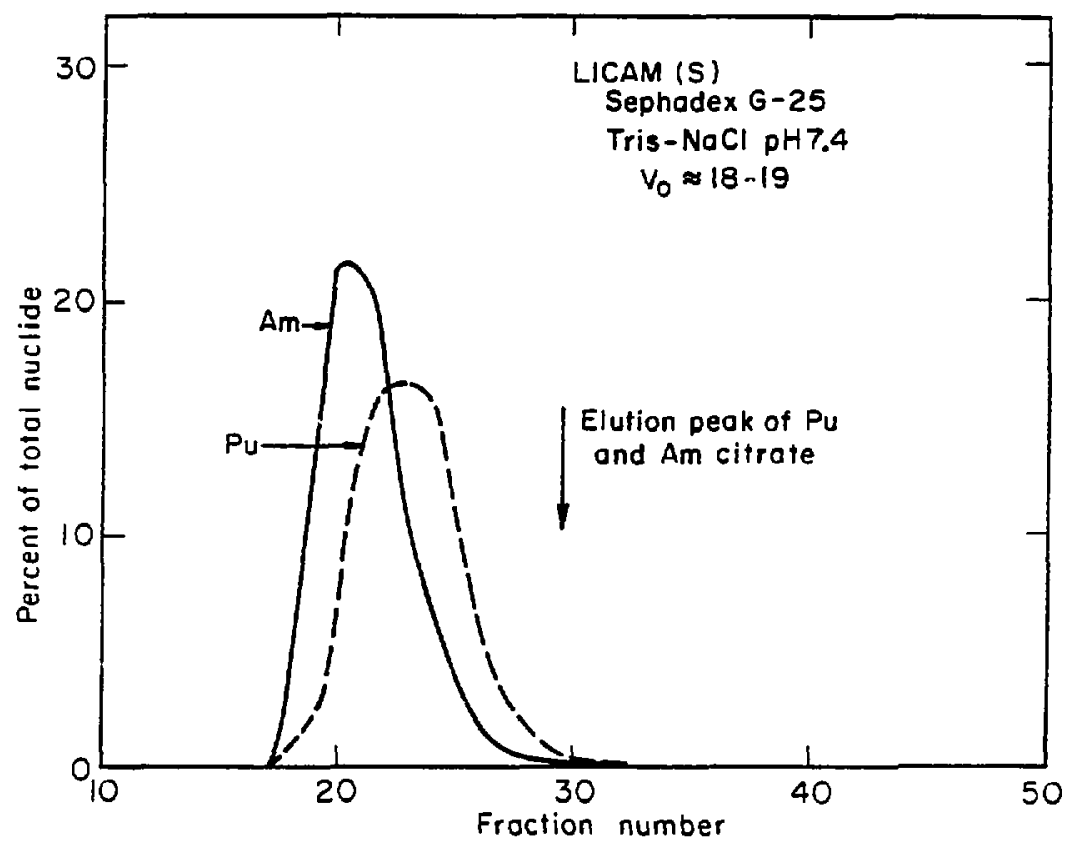

X日L8212-4325

Figure 16. 


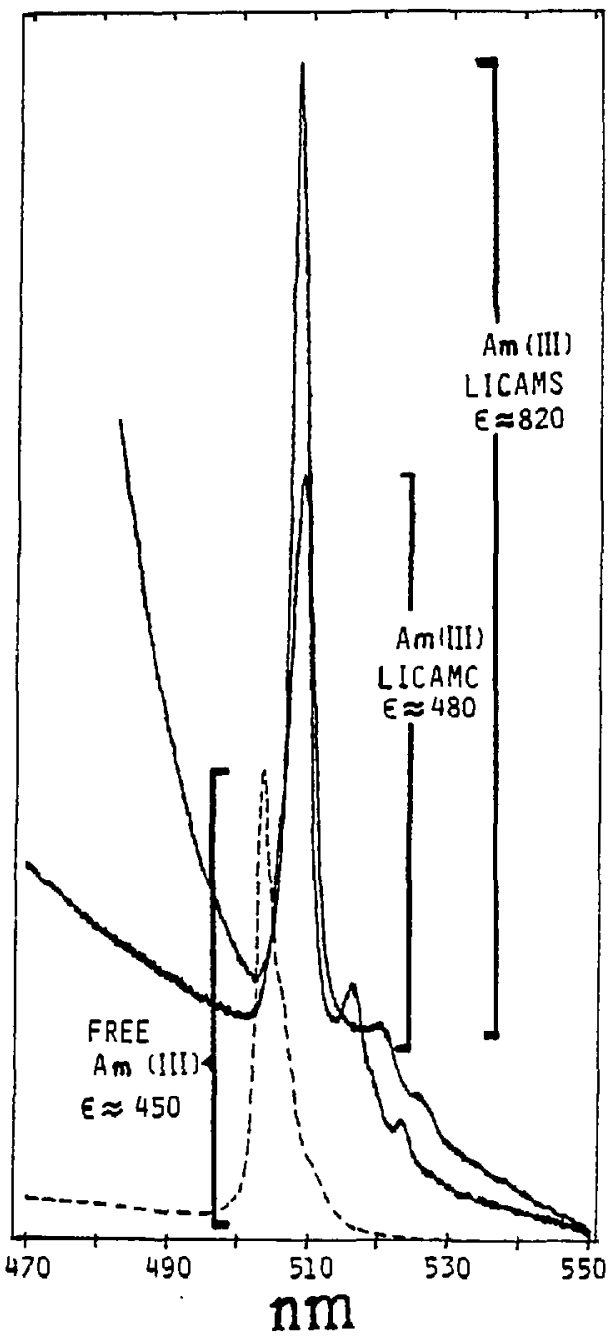

XBL 837-10657

Figure 17. 
Surmary of An(III) Spectra

$\begin{array}{llc} & \begin{array}{c}\text { Band } I^{a} \\ n m\end{array} & \begin{array}{c}\text { Band II } \\ n m\end{array} \\ \text { Free } \operatorname{Am}(I I I) & 503(450) & 812(77) \\ & & \\ \text { Am(III) }(3,4,3 \text {-LICAMS }) & 507(822) & 815(80) \\ & 516(97) & \\ & 523(24) & \\ \text { Am(III)(3,4,3-LICAMC }) & 508(482) & 830(126) \\ & 520(59) & \end{array}$

${ }^{a}$ Sharp band and satellites. Extinction coefficients in units of $\mathrm{H}^{-1} \mathrm{~cm}^{-1}$ are in parentheses.

Broad band. Extinction coefficients in units of $\mathrm{M}^{-1} \mathrm{~cm}^{-1}$ are in parentheses.

Figure 18 . 


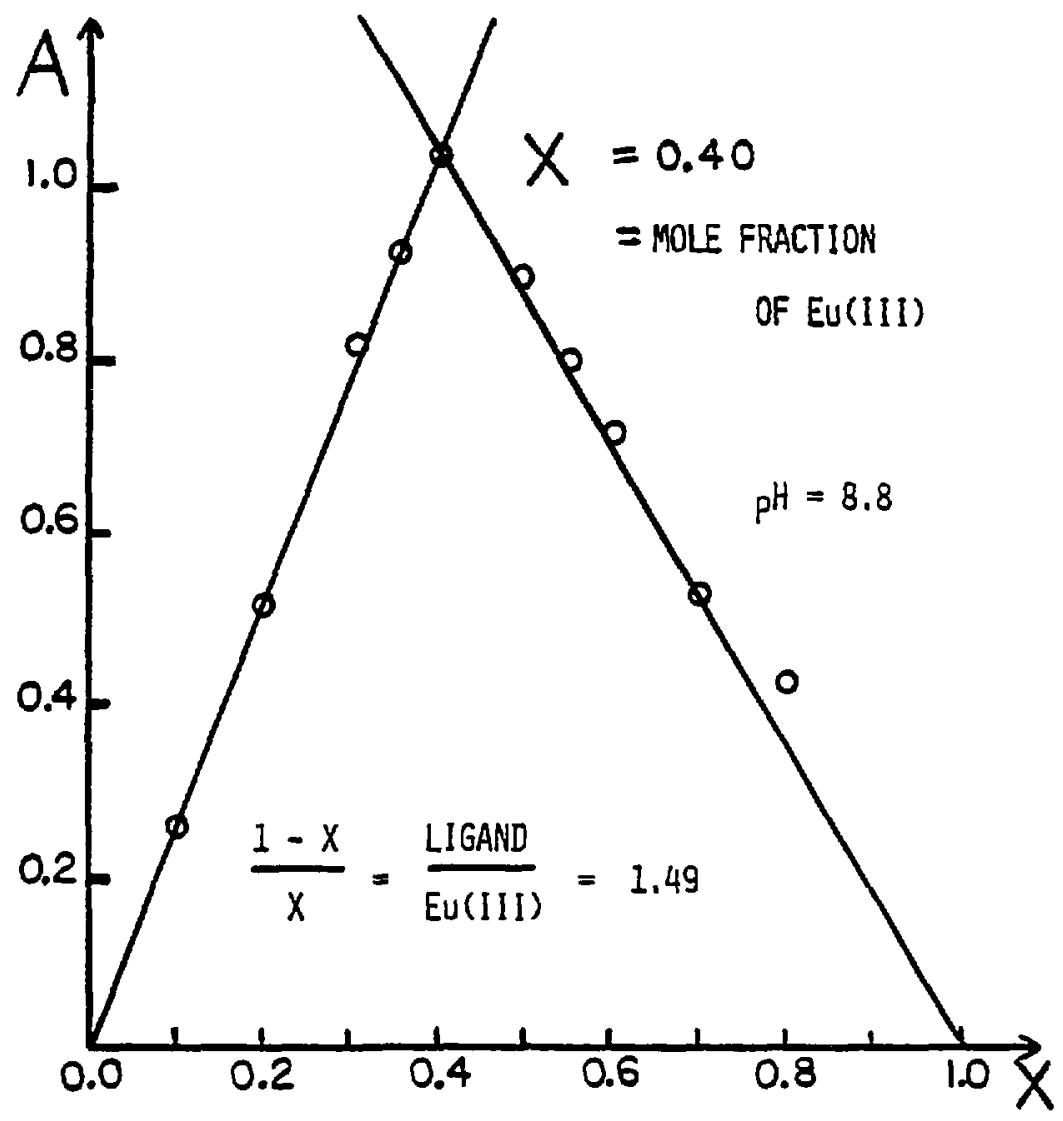

XBL 837-10693

Figure 19. 
This report was done with suppon from the Department of Energy. Any conclusions or opinions expressed in this repon represent solely those of the aurhor(s) and not necessarily those of The Regents of the Lniversity of California, the Laurence Berkeley Laboratory or the Department of Energy.

Reference to a company or product name does not imply approval or recommendation of the product by the University of California or the U.S. Department of Energy to the exclusion of others that may be suitable. 